\title{
Some Alternatives? Event-Related Potential Investigation of Literal and Pragmatic Interpretations of Some Presented in Isolation
}

\author{
Cécile Barbet * and Guillaume Thierry \\ School of Psychology, Bangor University, Bangor, UK
}

In sentence verification tasks involving under-informative statements such as Some elephants are mammals, some adults appear more tolerant to pragmatic violations than others. The underlying causes of such inter-individual variability remain however essentially unknown. Here, we investigated inter-individual variation in adults deriving the scalar inference "not all" triggered by the quantifier some. We first assessed the individual intolerance to pragmatic violations in adult participants presented with under-informative some-statements (e.g., Some infants are young). We then recorded event-related brain potentials in the same participants using an oddball paradigm where an ambiguous deviant word some presented in isolation had to be taken either as a match (in its literal

OPEN ACCESS

Edited by:

Karsten Steinhauer,

McGill University, Canada

Reviewed by:

Robert Fiorentino,

University of Kansas, USA

John E. Drury,

Stony Brook University, USA

${ }^{*}$ Correspondence:

Cécile Barbet

c.barbet@bangor.ac.uk

Specialty section:

This article was submitted to

Language Sciences,

a section of the journal

Frontiers in Psychology

Received: 03 June 2016 Accepted: 14 September 2016

Published: 30 September 2016

Citation:

Barbet C and Thierry G (2016) Some Alternatives? Event-Related Potential Investigation of Literal and Pragmatic Interpretations of Some Presented in

Isolation. Front. Psychol. 7:1479.

doi: 10.3389/fpsyg.2016.01479 interpretation "at least some") or as a mismatch (in its pragmatic interpretation "some but not all") and where an unambiguous deviant target word all was featured as control. Mean amplitude modulation of the classic P3b provided a measure of the ease with which participants considered some and all as deviants within each experimental block. We found that intolerance to pragmatic violations was associated with a reduction in the magnitude of the P3b effect elicited by the target some when it was to be considered a literal match. Furthermore, we failed to replicate a straightforward literal interpretation facilitation effect in our experiment which offers a control for task demands. We propose that the derivation of scalar inferences also relies on general, but flexible, mismatch resolution processes.

Keywords: scalar inferences, inter-individual variation, pragmatic tolerance, systemizing, event-related potentials, P3b

\section{INTRODUCTION}

Understanding the meaning of sentences involves two kinds of processes: (i) decoding literal meaning and (ii) deriving inferences that go beyond the literal meaning of words and clauses (implicatures, see e.g., Grice, 1968). For example, in:

(1) Anna: Did the children's summer camp go well? Bob: Some of them got stomach flu.

a. More than one child/at least some of the children got stomach flu.

b. Not all the children got stomach flu.

c. The summer camp didn't go as well as hoped (from Carston, 2004). 
while the literal meaning of Bob's answer is (1-a), Anna can infer from his answer both (1-b) and (1-c). According to Gricean terminology (see e.g., Grice, 1968; Levinson, 2000), (1-b.) is a generalized conversational implicature because it is triggered by a specific item (some) and is assumed to arise generally across contexts; while (1-c) is a particularized conversational implicature because it crucially depends on the context. Indeed if Anna's question had been "Were all children able to sit their exams?" for example, the inference (1-c) would not arise; whereas if Anna's question concerned the exams rather than the summer camp (1-b) would still hold.

Generalized inferences such as (1-b) are called scalar inferences (hereafter SIs) because they are triggered by linguistic expressions which have stronger competitors on scales of informativeness (see Horn, 1972, 1989). For instance, in (1), some contrasts with all and thus can trigger the SI "not all." Other examples of lexical scales are 〈always, sometimes〉, 〈and, or $\rangle$, $\langle$ finish, start〉, 〈impossible, difficult〉 (see e.g., van Tiel et al., 2016).

In Gricean pragmatics, drawing an SI requires at least two steps (see e.g., Katsos and Bishop, 2011; Bott et al., 2012; Breheny et al., 2013). First, the hearer determines whether the speaker could have made a more informative (i.e., stronger) statement; then she negates the alternative statement because she assumes that the speaker would have chosen the stronger statement if it had been true. In certain semantic contexts, e.g., antecedents of conditionals (see "downward entailing" contexts in Chierchia, 2004), such as:

If some of the students fail the test, their teacher will be disappointed (Katsos et al., 2005, p. 1108) .

it is not expected that the SI will be drawn since an alternative sentence with a stronger term would be informatively weaker (see e.g., Hartshorne et al., 2015; Politzer-Ahles and Gwilliams, 2015). Moreover, depending on context, the hearer may or may not negate the alternative statement when it is stronger according to assumed speaker knowledge in a second step, also called the epistemic step (see e.g., Breheny et al., 2013). Therefore, we can expect a hearer of:

At my client's request, I skimmed the investment report. Some of the real estate investments lost money (Bergen and Grodner, 2012).

to stick to the literal meaning of some because the speaker is assumed to have insufficient knowledge of the situation to warrant the use of the stronger alternative all. On the contrary, a hearer of:

At my client's request, I meticulously compiled the investment report. Some of the real estate investments lost money (Bergen and Grodner, 2012).

should draw the SI, since the speaker can be inferred to have exhaustive information about the case.

Scalar inferences have become the test case in experimental pragmatics for more than a decade in the debate opposing tenets of possible automatic inference derivation (the "default models," inspired by Levinson, 2000; Chierchia, 2004) and tenets of context-dependency, arguing that generalized implicatures do not exist (the "context-driven models," inspired by Carston, 1995; Sperber and Wilson, 1995). SI context-sensitivity has been shown in a number of experimental studies (see e.g., Breheny et al., 2006; Bergen and Grodner, 2012; Politzer-Ahles and Fiorentino, 2013; Hartshorne et al., 2015), but expected delays or processing costs associated with their derivation have not always been observed (see e.g., Grodner et al., 2010; Breheny et al., 2013; Politzer-Ahles and Fiorentino, 2013; Degen and Tanenhaus, 2015; Hartshorne et al., 2015). Consequently, a constraint-based formulation of context-driven models has been proposed according to which SI derivation can appear default-like when enough linguistic and contextual cues are present and reduce processing delay or cost (see Grodner et al., 2010; Degen and Tanenhaus, 2011, 2015).

However, models in experimental pragmatics have paid less attention to inter-individual variation (but see Feeney et al., 2004; Nieuwland et al., 2010; Antoniou and Katsos, 2011; Heyman and Schaeken, 2015; Zhao et al., 2015). In sentence verification paradigms involving under-informative sentences such as:

$$
\text { Some elephants are mammals (Bott and Noveck, 2004). }
$$

some adult participants tend to consistently accept such underinformative statements that are literally true but pragmatically infelicitous (not just some, but all elephants are mammals) while other tend to consistently reject them (see e.g., Noveck and Posada, 2003; Feeney et al., 2004; Antoniou and Katsos, 2011; Hunt et al., 2013). This led to a distinction between "literal" (or "logical") and "pragmatic" responders. Moreover, because rejecting under-informative statements took more time than accepting them, it was assumed that literal responses did not require computation of the SI. However, in Feeney et al. (2004) or Antoniou and Katsos (2011), participants needed more time to accept under-informative some-statements than informative some-statements such as:

$$
\text { Some men have beards (Feeney et al., 2004). }
$$

Such a result is not expected if one assumes that the SI is not computed at all in the case of literal responses to underinformative statements. Therefore, Antoniou and Katsos (2011) proposed that all adult participants are sensitive to violations of informativeness and thus, that all consider whether or not a more informative statement with a stronger expression could have been used. Katsos and Bishop (2011, p. 77) stressed that responses to under-informative statements in forced-choice paradigms may also reflect a metalinguistic decision to "reject the utterance as worse than optimal or to accept it as better than false." That being said, a consistently literal vs. pragmatic response pattern could also reflect a desire of within-task consistency on the part of participants. Indeed, since the test sentences can be interpreted as either true or false and the choice is forced, participants may initially randomly opt for true or false and then stick to their initial choice in order to maintain idiosyncratic consistency (see also Tavano and Kaiser, 2010).

Since they are able to fully derive SIs, one wonders why some adult participants accept under-informative statements at all. If a 
literal or pragmatic response pattern ${ }^{1}$ is not essentially accounted for by different strategic and/or metalinguistic processes, one hypothesis is that participants who are led to interpret some literally or pragmatically might experience some difficulty shifting from one to the other interpretation. Here we sought to obtain an independent, quantitative, and objective measure of pragmatic or literal functioning in participants construed as pragmatic or literal on the basis of their performance in a sentence evaluation task, using event-related potentials (ERPs).

Previous ERP studies using under-informative segments have provided some evidence that pragmatically skilled participants (as indexed by sub-scale(s) of the Autism-Spectrum Quotient questionnaire) are more sensitive to violations of informativeness than their less pragmatically skilled peers (Nieuwland et al., 2010, N400 study; Zhao et al., 2015, MMN study). To our knowledge, no study to date has investigated inter-individual variation in participants led to behave pragmatically or literally. In the present study, we invited participants to consider some in its literal or pragmatic sense via direct instruction (see also Bott and Noveck, 2004; Bott et al., 2012; Tomlinson et al., 2013) rather than constrain the interpretation of some based on cues derived from the linguistic context. This is because conditions are never fully comparable even when considering elegantly designed studies in which context control was maximal. For instance, in PolitzerAhles and Fiorentino (2013) and Politzer-Ahles and Gwilliams (2015), any vs. all were used in the contexts preceding some. However, any and some are more strongly associated than all and some (see e.g., the Edinburgh Associative Thesaurus Kiss et al., 1973) leading to the any-contexts possibly being more predictive of some than the all-contexts. Moreover, in order to focus the quantitative ERP measure on the critical word some, we resorted to present it in isolation. Furthermore, we used a pragmatically unambiguous stimulus all as control whereas the ambiguous stimulus some was to be considered in its literal (at-least-some) or its pragmatic (some-but-not-all) sense depending on instruction given at the onset of each experimental block.

The P300 wave (or P3, see e.g., Luck, 2005; Polich, 2007) which is a positive-going ERP deflection peaking between 250 and $500 \mathrm{~ms}$ (or even later depending on experimental parameters, see e.g., Picton, 1992; Polich, 2007) is commonly elicited by deviant stimuli in oddball paradigms. In an oddball paradigm, stimuli of lower relative probability called deviants are presented within pseudo-randomly structured streams of higher relative probability stimuli called standards. Participants are usually asked to detect a particular type of deviant stimulus called target. Target detection is classically associated with an instance of the P300 -the P3b- maximal over parietal areas of the scalp, commonly accepted as an index of conscious target detection and working memory updating (see e.g., Donchin, 1981; Polich, 2007). In the present study, we used the P $3 \mathrm{~b}$ as an index of targetlikeness for the words all and some, the latter depending on the instructions provided to the participant at the beginning of each block. In other words, the P3b provided a quantitative, objective,

\footnotetext{
${ }^{1}$ Note that in fact the response pattern does not always appear bimodal and that some participants can be wholly inconsistent within an experiment. However, criteria for grouping participants vary from one study to another, and interindividual variation is not always reported.
}

and context-free measure of the ease with which participants implemented the pragmatic or literal interpretation of some, when instructed to do so. Thus, we expected the amplitude of the P3b to increase proportionally to the target-likeness of some under different instructions, that is, it would measure the effectiveness with which participants acted pragmatically or literally. Furthermore, the absence of a "pragmatic N400" in the study by Nieuwland et al. (2010) might relate to strategic effects: Participants who show no significant "pragmatic N400" might have rapidly become aware that half of the sentences starting with some were strange and made sense only after the comma. This might have reduced N400 amplitude because under-informativeness gradually became more expected with time. The P3b is thus arguably a better index since its amplitude does not decrease with time.

In the ERP experiment, participants were presented with single quantifiers or numerals (ALL, SOME, ONE, TWO, NONE, or THREE), printed in white and green letters on a black background. Sometimes the number of green letters within a word stimulus matched its meaning (e.g., ALL printed with all of its three letters in green) and sometimes there was a mismatch (e.g., ALL printed with only some of its letters in green). In half of the blocks, participants were instructed to consider the word SOME printed with all its letters in green (ambiguous-SOME) as a mismatch (because not some, but all letters are green) and in the other blocks as a match (because if all of its letters are green, then some of them necessarily are). The unambiguous match or mismatch stimulus ALL served as control and we manipulated the ratio of match and mismatch stimuli so as to obtain an oddball distribution prone to eliciting a P3b. Experimental blocks were of two types, based on whether participants had to detect match words within a stream of mismatch ones (match target blocks) or mismatch words within a stream of match ones (mismatch target blocks). The full design of the ERP experiment is depicted in Table 2 in Section 2.2.2.

Before being engaged in the oddball paradigm, participants completed a questionnaire assessing their pragmatic tolerance based on acceptability judgements (how strongly they agree or disagree with under-informative statements such as "Some circles are round"). The questionnaire also assessed Autism-Spectrum Quotient, Empathy Quotient, Interpersonal Reactivity Index and Systemizing Quotient in order to shed light on the personality traits or cognitive style that could account for tolerance or intolerance to pragmatic violations.

From a behavioral point of view, in the ERP experiment, we expected a general facilitation effect when some was to be taken in its literal interpretation as observed in a number of previous studies (see e.g., Noveck and Posada, 2003; Bott and Noveck, 2004; De Neys and Schaeken, 2007; Chevallier et al., 2008; Bott et al., 2012). We did not have any prediction regarding possible relationships between the participants' pragmatic tolerance as measured by the questionnaire and behavioral data. In contrast, we expected to find a relationship between pragmatic tolerance and the magnitude of the P3b effect elicited by the critical ambiguous stimulus SOME, depending on whether it was to be considered literal or pragmatic. More specifically, if SOME was to be taken literally, we expected the magnitude of the P3b effect to 
be particularly pronounced for literal responders and less so for pragmatic ones, whereas the reverse pattern should be observed when SOME was to be taken pragmatically.

\section{METHODS}

\subsection{Participants}

Fifty-two native speakers of English ( 33 females; mean age $=21.2$, $S D=4.7)$ gave written consent to take part in the experiment approved by the Ethics Committee of Bangor University, United Kingdom. All were students from the School of Psychology and were given course credits for their participation. All had normal or corrected-to-normal vision. No EEG data was recorded for one participant due to a technical fault and the data of 12 participants had to be dismissed due to excessive artifacts (see Section 2.4 for details). Therefore, statistical analyses of ERP results are based on 39 individual datasets, and behavioral results (reaction times and accuracy) on 38 individual datasets because one behavioral dataset was missing due to a technical error.

\subsection{Materials}

\subsubsection{Questionnaire}

The questionnaire comprised the 50 statements of the AutismSpectrum Quotient questionnaire (henceforth AQ), the 60 statements of the Empathy Quotient questionnaire (EQ), the 75 statements of the Systemizing Quotient-Revised questionnaire (SQ-R), the 28 statements of the Interpersonal Reactivity Index (IRI) and 40 all- or some-statements.

The AQ, EQ, IRI, and SQ-R are self-report questionnaires for use with adults with normal intelligence.

The AQ measures the degree to which a person presents the traits associated with the autistic spectrum (Baron-Cohen et al., 2001). It includes 10 statements from the 5 following sub-scales: social skill, attention switching, attention to detail, imagination and communication. Given the topic of this study and the results obtained by Nieuwland et al. (2010), we focused on the communication sub-scale of the AQ.

The EQ measures individual differences in empathy (BaronCohen and Wheelwright, 2004). It comprises 40 empathy items and 20 filler items. The EQ does not distinguish affective from cognitive empathy; nevertheless, SI derivation does not appear related to affective empathy but rather to some form of mindreading akin to cognitive empathy (see e.g., Pijnacker et al., 2009). Therefore, we also included the IRI, which is another instrument developed in order to measure individual differences in empathy, assessing 4 different areas (with 7 items per area): empathic concern, personal distress, fantasy, and perspective-taking (Davis, 1980, 1983). The first two areas concern affective empathy whilst the two others relate to cognitive empathy. Since step 2 of SI derivation entails evaluating the epistemic state of the speaker, we focused on the perspective-taking sub-scale.

Finally, the SQ- $R$ measures individual differences in systemizing, that is the ability to analyse systems, extract rules, and predict system outputs (Wheelwright et al., 2006; Baron-Cohen, 2008, 2009, 2011). We included this measure to test the hypothesis that high systemizing ability can help reject under-informative statements. This idea arose from our reading of studies investigating high-functioning individuals with autism and Asperger's syndrome (e.g., Pijnacker et al., 2009), individuals who are very good at systemizing (see e.g., Wheelwright et al., 2006). Despite their associated high score on the AQ communication sub-scale, they appear to derive SIs as often as control participants, although the high AQ communication score predict poorer pragmatic skills (Pijnacker et al., 2009; Chevallier et al., 2010; see also Nieuwland et al., 2010, p. 343).

The 40 all- or some-statements were either true or false but, in the case of some-statements, possibly under-informative (i.e., logically true but pragmatically infelicitous). There were 10 such some-statements, 10 true and 10 false control all-statements, and 5 true and 5 false control some-statements. We computed a Pragmatism score on the basis of the responses to the 10 underinformative some-statements. As in Noveck (2001) and Feeney et al. (2004), participants were randomly assigned to one of two lists in order to minimize item-driven effects ${ }^{2}$ (see Table $\mathbf{1}$ for examples of statements and Table A1 in Appendix A for the full lists). Some of the statements were taken from previous studies (Noveck and Posada, 2003; Feeney et al., 2004; Banga et al., 2009; Nieuwland et al., 2010).

Participants were asked to choose between "strongly agree," "slightly agree," "slightly disagree," or "strongly disagree" in response to each statement (we adapted the 5-level scale of the IRI to fit this scale used in the AQ, EQ, and SQ-R). The all- and somestatements were mixed with AQ, EQ, SQ-R, and IRI statements so as to reduce consistency within-task effects (see Section 1, see also Feeney et al., 2004, p. 127). We thus used the same 4-level scale for the all-and some-statements as for the AQ, EQ, SQ-R, and IRI statements. Furthermore, we assumed that using a 4-level scale for critical under-informative some-statements might increase sensitivity as compared to a binary forced-choice (true/false). "Strongly agree" answers to these statements were scored 0 , "slightly agree" answers were scored 1 , "slightly disagree" answers were scored 2 and "strongly disagree" answers were scored 3. Therefore, the range of Pragmatism score was 0-30, low scores indicating tolerance to pragmatic violations and high scores indicating intolerance to such violations.

\subsubsection{ERP Experiment}

Using the words all, some, none, one, two, and three we constructed 12 stimuli using white and green letters, the number of green letters being consistent or not with the meaning of the word (see Figure A1 in Appendix B). Using a bold typeface to represent letters presented in green and a light typeface to represent letters presented in white, match stimuli were: ALL, SOME, NONE, ONE, TWO, THREE, and mismatches were: ALL, SOME, ONE, NONE, TWO, THREE. In addition, SOME was used as the ambiguous test stimulus, since it could be interpreted either literally (a match) or pragmatically (a mismatch).

\footnotetext{
${ }^{2}$ We followed the same procedure as in Noveck (2001) and Feeney et al. (2004) : by switching the quantifier, true universals of list one became test existentials in list two, and test existentials of list one became true universal in list two; 5 false universals of list one the 5 true existentials in list two, and the 5 true existentials of list one 5 false universals in list two.
} 
TABLE 1 | Examples of all- and some-statements used in the questionnaire.

\begin{tabular}{ll}
\hline Condition & Example \\
\hline Test existentials & Some circles are round \\
True universals & All infants are young \\
False universals & All animals are black \\
True existentials & Some children are blonde \\
False existentials & Some books are good to eat \\
\hline
\end{tabular}

There were 4 experimental blocks conforming to the structure of a classic oddball design. Two blocks were match target blocks in which most stimuli were mismatches and infrequent ones were matches, which were the blocks' targets, and 2 blocks were mismatch target blocks in which standards were matches and infrequent mismatches were the targets. Ambiguous-SOME (SOME) appeared in both the block types with its status as target or standard depending on the instructions given to the participants at the beginning of each block (see Section 2.3).

The experiment thus conformed to a $2 \times 2$ factorial design manipulating Block type (match target or mismatch target) and Instructions (pragmatic or literal interpretation of some, and consequently target or standard status of some in the block). Within each block (match target - pragmatic some, match targetliteral some, mismatch target-pragmatic some and mismatch target-literal some) participants saw: 30 control target-ALL, 30 ambiguous-SOME, and 18 filler targets NONE, ONE, TWO, THREE and SOME. A target or an ambiguous-SOME stimulus was preceded by 3,4 , or 5 pseudo-randomly selected standards (312 in total, 52 of each individual type). There was thus 390 stimuli per block, that is, 312 standards, 30 control targets ALL, 30 ambiguous-SOME, and 18 filler targets. In other words, $20 \%$ of the stimuli were deviant targets in the two conditions in which ambiguous-SOME was a target, and $12.3 \%$ in the two conditions in which ambiguous-SOME was a standard, see Table 2 below.

\subsection{Procedure}

During EEG cap installation, participants rated a random sequence of the 253 statements of the questionnaire. They were instructed to indicate how strongly they agreed or disagreed with each statement by pressing one of 4 buttons on a response box. They were told that there was no right or wrong answer ${ }^{3}$. Participants generally needed 20-30 min to complete the questionnaire, which generally provided enough time to set the EEG cap.

Participants were then instructed to monitor stimuli presented in the center of a 19" CRT monitor in Arial Narrow size 14 points subtending around $1^{\circ}$ of visual angle and to press a button if the stimulus differed from the most common type presented within a block. For instance in the match target-pragmatic some block, participants were instructed to press a button for match stimuli (such as ALL or ONE) and ignore mismatch stimuli (such as ALL, SOME, NONE, ONE, TWO, THREE). They were

\footnotetext{
${ }^{3}$ The instructions were "Please read each statement carefully and rate how strongly you agree or disagree with it by pressing the corresponding button. There are no right or wrong answers. Please answer as spontaneously as possible."
}

TABLE 2 | Design of the ERP experiment.

\begin{tabular}{|c|c|c|c|c|}
\hline \multirow{2}{*}{$\begin{array}{l}\text { Instruction } \\
\text { Block type }\end{array}$} & \multicolumn{2}{|c|}{ some literal } & \multicolumn{2}{|c|}{ some pragmatic } \\
\hline & $\begin{array}{l}\text { Match } \\
\text { target }\end{array}$ & $\begin{array}{l}\text { Mismatch } \\
\text { target }\end{array}$ & $\begin{array}{l}\text { Match } \\
\text { target }\end{array}$ & $\begin{array}{l}\text { Mismatch } \\
\text { target }\end{array}$ \\
\hline \multirow[t]{7}{*}{ Target stimuli } & SOME & & & SOME \\
\hline & $A L L$ & AЦ & $A L L$ & A凹 \\
\hline & SOME & SOME & SOME & SOME \\
\hline & NONE & NONE & NONE & NONE \\
\hline & ONE & ONE & ONE & ONE \\
\hline & TWO & TWO & TWO & TWO \\
\hline & THREE & THREE & THREE & THREE \\
\hline \multirow[t]{7}{*}{ Standard stimuli } & & SOME & SOME & \\
\hline & ALL & ALL & ALL & ALL \\
\hline & SOME & SOME & SOME & SOME \\
\hline & NONE & NONE & NONE & NONE \\
\hline & ONE & ONE & ONE & ONE \\
\hline & TWO & TWO & TWO & TWO \\
\hline & THREE & THREE & THREE & THREE \\
\hline
\end{tabular}

particularly instructed about SOME, which was to be considered a mismatch (and thus ignored) because "not some, but all letters are in green." In the match target-literal some block, instructions were the same as above, with the exception of the particular instruction about SOME, which was to be considered a match (and thus a target) because "some letters are indeed green." The pragmatic some and literal some mismatch target blocks were a mirror image of the two previously described ones, such that standards were now match stimuli (ALL, SOME, NONE, ONE, TWO, THREE) and targets were mismatch stimuli (e.g., ALL, THREE). Under pragmatic instruction, SOME was thus to be considered a mismatch target and responded to, and under literal instruction it was to be considered a match standard and ignored, hence its instruction-dependent status.

Block types (match target or mismatch target) order and Instructions (literal or pragmatic interpretation of some first) were rotated between participants ( 8 combinations). Response side was counterbalanced between participants. There was a break between blocks and a short familiarization with specific instructions at the beginning of each block. Each stimulus was presented for $1300 \mathrm{~ms}$ or until participant's response, whichever was the shortest, with a randomly selected inter-stimulus interval of $160,180,200,220$, or $240 \mathrm{~ms}$ to reduce cross-trial ERP contamination. Participants needed around $40 \mathrm{~min}$ to complete the task.

\subsection{EEG Recording and Analysis}

Electrophysiological data were recorded continuously at a rate of $1 \mathrm{kHz}$ in reference to electrode $\mathrm{Cz}$ from $64 \mathrm{Ag} / \mathrm{AgCl}$ electrodes using SynAmp2 amplifiers (Neuroscan Inc., El Paso, TX, USA). Electrodes were attached to an elastic cap (Easycap ${ }^{\mathrm{TM}}$, Herrsching, Germany) and placed according to the extended 10-20 convention. The ground electrode was placed at FPZ. Bipolar electrodes were placed to the left of the left eye and to 
the right of the right eye (HEOG) and above and below the right eye (VEOG). Signals were filtered on-line between 0.01 and 200 Hz. Impedances were kept below $5 \mathrm{k} \Omega$ for the 64 electrodes and below $10 \mathrm{k} \Omega$ for the eye electrodes. Before segmentation, the EEG was processed through a low-pass filter with a cutoff frequency of $20 \mathrm{~Hz}$ and a high-pass filter of $0.1 \mathrm{~Hz}$. Eye blinks were mathematically corrected based on the procedure advocated by Gratton et al. (1983) . After correction, any trial with amplitude exceeding $\pm 100 \mu \mathrm{V}$ at any point within an epoch and at any recording site except VEOG and HEOG was discarded from analysis. The EEG was then segmented into epochs ranging from -100 to $1000 \mathrm{~ms}$ after stimulus onset. Baseline correction was performed in reference to pre-stimulus activity, and individual averages were digitally re-referenced to the global average reference. EEG data processing was done using Scan Edit 4.5 (Neuroscan Inc.). Twelve individual datasets were discarded due to excessive noise and/or alpha contamination leading to undetectable early components (P1-N1 complex) in two or more of the blocks. In the remaining 39 datasets, one block was missing due to a technical error and one block with less than 17 accepted trials was discarded, leading to an average number of trials per condition of $28.6(S D=2)$.

We expected a delayed P300 effect because of the nature of the task (see e.g., Fosker and Thierry, 2005; Delplanque et al., 2006; Polich, 2007; Thierry and Kotz, 2008; Otterbein et al., 2012; Wu and Thierry, 2013; Sassenhagen et al., 2014). Differences in the early P300 range (P3a) were not analyzed because no clearly differentiated peak was identified. Inspection of the grandaverage ERP waveforms at the predicted electrode location of maximal amplitude (Pz, see e.g., Duncan-Johnson and Kopell, 1981; Polich, 2007; Sassenhagen et al., 2014) revealed that the main peak in the later P300 range (P3b) was delayed by about 100 $\mathrm{ms}$ in the mismatch target as compared to the match target blocks (grand-average peak latencies 620 and $515 \mathrm{~ms}$, respectively). This delay could be expected considering reaction times differences between blocks (see Section 3.2.2). P3b mean amplitudes were computed and analyzed in 150 ms-wide windows around the average peak latency calculated in match and mismatch block types separately: 440-590 ms in match target blocks and 550$700 \mathrm{~ms}$ in mismatch target blocks, based on visual inspection of variations of the Mean Global Field Power measured across the scalp (Picton et al., 2000; Luck, 2005). P3b mean amplitudes were measured at electrode locations $\mathrm{Pz}, \mathrm{POZ}, \mathrm{PO} 3, \mathrm{PO} 4$.

\section{RESULTS}

\subsection{Pragmatism Score}

Out of a maximum of 30, Pragmatism scores of the 39 participants kept for statistical analyses of ERP results ranged from 0 to $29(M=5.48, S D=8.35)$. Pragmatism scores did not allow us to split the participants into two groups (pragmatic vs. literal responders) because 8 of them scored the median value of 1 .

\subsection{Behavioral Results}

\subsubsection{Accuracy}

Hit rates were high overall $(91.3 \%, S D=28.2)$. The proportions of correct responses per block types (match target and mismatch target) and stimulus conditions (target-ALL and ambiguous-SOME, the latter could be considered either a target or a standard depending on the blocks' instructions) are presented in Figure 1.

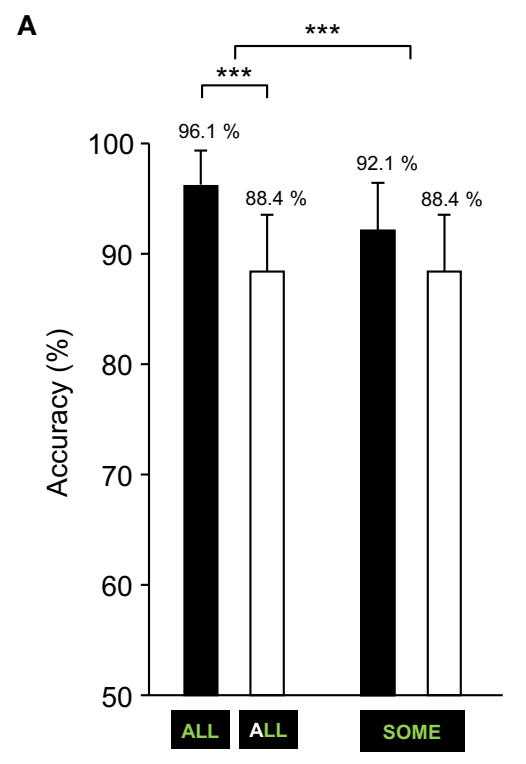

B
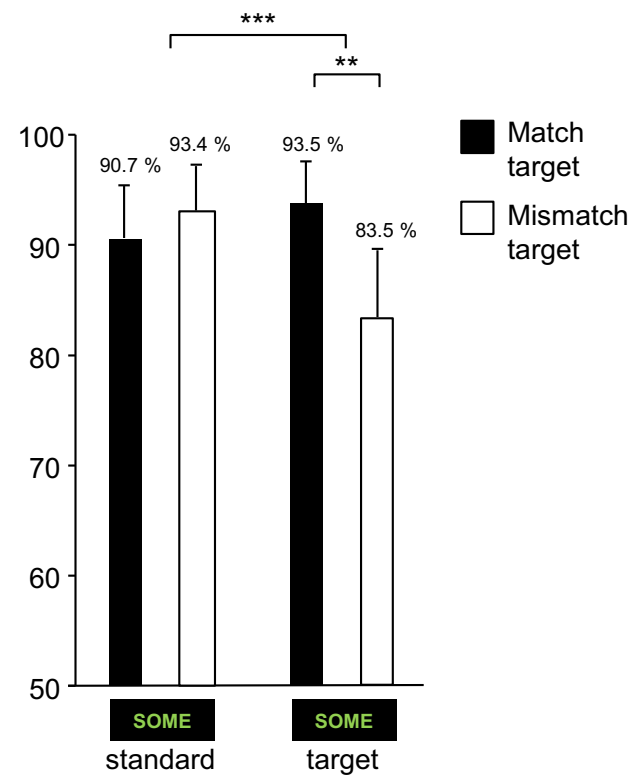

FIGURE 1 | Correct responses to target-ALL and ambiguous-SOME depending on the match or mismatch target Block type (error bars represent SEM). (A) Correct responses to target-ALL and ambiguous-SOME. (B) Correct responses to ambiguous-SOME depending on its status in the block (standard or target). ${ }^{\star \star \star} p<0.001,{ }^{\star \star} p<0.01,{ }^{*} p<0.05$. 
Hit rates were analyzed using logit mixed models ${ }^{4}$ (see e.g., Jaeger, 2008) including the maximal random effect structure justified by the design and by model comparison ${ }^{5}$, namely by-subject random intercepts and by-subject random slopes for Block type for all models.

The first model revealed a significant Block type $\times$ Stimulus interaction $(z=5.24, p<0.001)$, see Figure 1A. Analyses for the stimuli separately showed a significantly higher accuracy in match relative to mismatch target blocks for target-ALL $(z=5.48, p<0.001)$, see Figure 1A. For ambiguous-SOME, there was a significant interaction Block type $\times$ Status (target or standard in the block) $(z=-7.47, p<0.001)$, see Figure 1B.

When SOME was intended as a target (literal interpretation in match target block, and pragmatic interpretation in mismatch target block), participants made more errors in the mismatch than match target block $(z=-3.1, p<0.01)$, see Figure 1B, there was no interaction with Pragmatism score. When SOME was intended as a standard, and thus was to be ignored (pragmatic interpretation in match target block, and literal interpretation in mismatch target block), there was no significant difference between mismatch and match target blocks $(z=1.36, p=0.18)$, see Figure 1B, nor any interaction with Pragmatism score.

\subsubsection{Reaction Times}

This analysis only concerns reaction times for the stimuli ALL and SOME to which participants had to respond, that is targetALL and target-SOME, in the blocks in which both were targets. Figure 2 depicts reaction times (in ms) per Block type and Stimulus.

Reaction times were analyzed using linear mixed models ${ }^{6}$ (see e.g, Bates, 2005; Baayen et al., 2008; Baayen and Milin, 2010) including maximal random structure justified by the design and supported by the data: by-subject random intercepts and bysubject random slopes for Block type $\times$ Stimulus (or for Block type or for Stimulus). Reaction times were transformed according to the Box-Cox power transformation ${ }^{7}: 1 / \operatorname{sqrt}(\mathrm{RT})$. The final models included removal of outliers (data points with absolute standardized residuals exceeding 2.5 standard deviations, see e.g, Baayen and Milin, 2010).

The first model showed a significant interaction between Block type and Stimulus $\left[F_{(1,37.17)}=4.16, p<0.05\right]^{8}$, see Figure 2. Separate analyses for the target stimuli showed a significant effect of Block type for target-ALL $\left[F_{(1,34.18)}=\right.$ 276.67, $p<0.001]$. This effect was found for target-SOME too $\left[F_{(1,34.36)}=165.77, p<0.001\right]$, however there was no interaction with Pragmatism score, even though such interaction could have been expected for this stimulus. The effect of Block type on reaction times for both target-ALL and target-SOME

\footnotetext{
${ }^{4}$ Logit mixed models fitted using the $\mathrm{R}$ (R Core Team, 2014) package lme4 (Bates et al., 2014).

${ }^{5}$ See e.g., Barr et al. (2013).

${ }^{6}$ Linear mixed models fitted using the R package lmerTest (Kuznetsova et al., 2014).

${ }^{7}$ We used the boxcox function of the R package MASS (see Venables and Ripley, 2002) to determine the suitable transformation.

${ }^{8} \mathrm{We}$ used the anova function of $l m e r T e s t$ which provides analysis of variance tables of type 3 with denominator degrees of freedom calculated based on Satterthwaite's approximation.
}

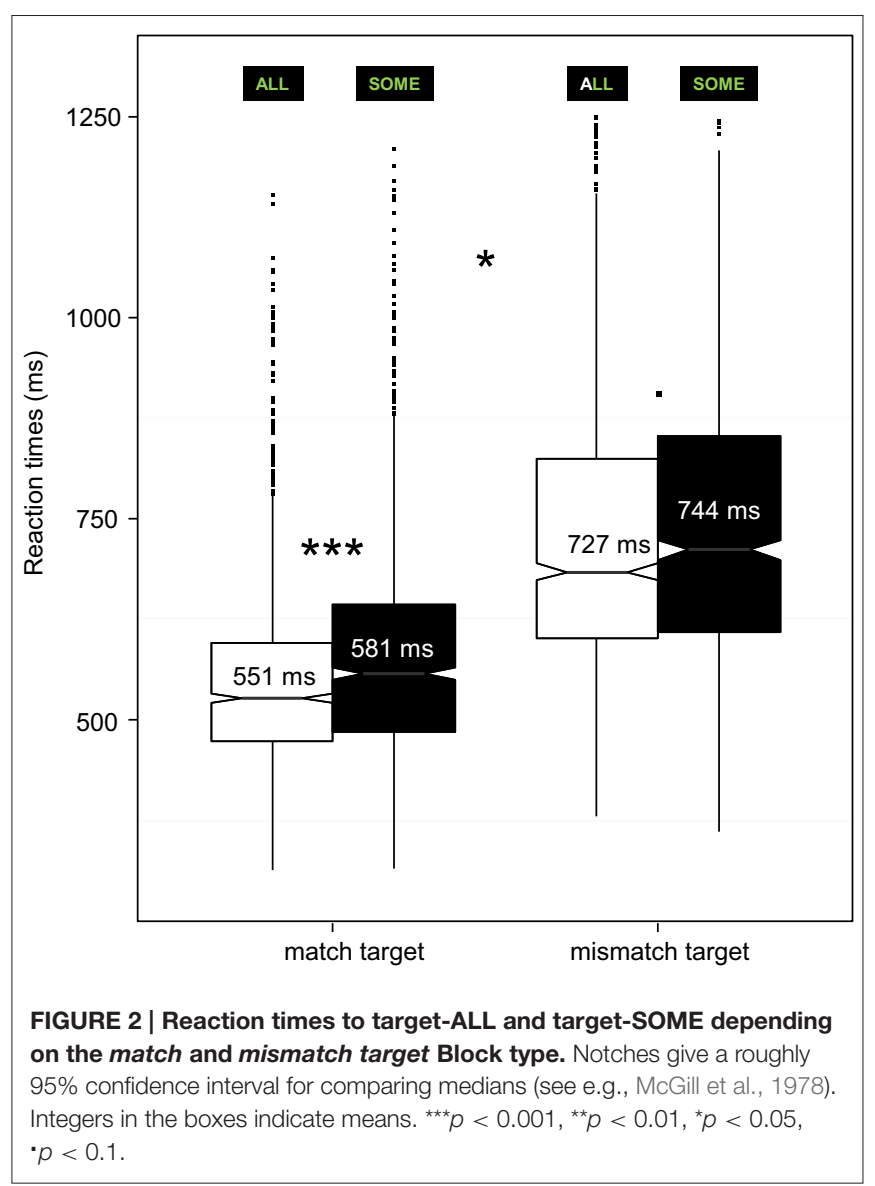

corroborates the facilitation effect of match target blocks observed on hit rates.

Analyses for the Block types separately showed a significant effect of target Stimulus in the match target block $\left[F_{(1,36.27)}=24, p<0.001\right]$. However, this effect was only marginal in the mismatch target block $\left[F_{(1,34.93)}=3.4, p=\right.$ 0.07]. There was no interaction with Pragmatism score, even though such an interaction could have been expected here also.

In sum, mismatch target detection led to longer reaction times than match target detection (by about $170 \mathrm{~ms}$ ). Furthermore, regardless of tolerance to pragmatic violations as indexed by Pragmatism score, when participants were instructed to take some in its literal interpretation (match target block), they needed more time to respond to target-SOME than to target-ALL (by about $30 \mathrm{~ms}$ ), but the difference between target-ALL and target-SOME was smaller (about $18 \mathrm{~ms}$ ) when they had to consider target-SOME in its pragmatic interpretation (mismatch target block). This suggests that the facilitation effect of the literal interpretation of target-SOME compared with its pragmatic interpretation observed on hit rates only reflects the general facilitation effect of the Block type (match target compared with mismatch target). Furthermore, the increase of accuracy accompanied by the slowdown of response speed (when comparing target-SOME with the control target-ALL) in the match target block resembles a speed-accuracy trade-off. 


\subsection{ERP Results (P3b)}

Grand-average ERP waveforms are displayed in Figure 3. Grand-average difference ERP waveforms and topographies of the P3b effect elicited by target-ALL and ambiguous-SOME are displayed in Figures 5, 6, respectively.

P3b mean amplitudes and P3b mean effects were analyzed using linear mixed models including maximal crossed random effects justified by the data (see Barr et al., 2013, and Sections $3.2 .1,3.2 .2)$. The random structures were kept maximal for all of the models, that is by-subject random intercepts with by-subject random slopes for all of the fixed effects, and by-electrode random intercepts, but for the first model of analysis of the P3b effects for which the complex random structure had to be simplified, see below. The final models included removal of outliers (data points with absolute standardized residuals exceeding 2.5 standard deviations, see Section 3.2.2).

We first analyzed the P3b mean amplitudes elicited by the 3 different Stimulus types (standard, target-ALL and ambiguousSOME) in the 4 experimental blocks, see Figure 3. We conducted the analyses by block because of the dual status of ambiguousSOME (target or standard, see left and right panels in Figure 3), and because the standards were different in the different Block types (mismatch or match target, see upper and lower panels in Figure 3).
In all four blocks, the effect of Stimulus type was significant (match target block with literal target-SOME, see Figure 3A: $F_{(2,38.13)}=30.71, p<0.001 ;$ match target block with pragmatic standard-SOME, see Figure 3B: $F_{(2,38.04)}=60.87$, $p<0.001$; mismatch target block with pragmatic target-SOME, see Figure 3C: $F_{(2,37.04)}=28.16, p<0.001$; mismatch target block with literal standard-SOME, see Figure 3D: $\left.F_{(2,37.07)}=10.88, p<0.001\right)$; differences between stimuli with estimates of the mixed models in $\mu \mathrm{V}$ and $p$-values adjusted are presented in Table 3, and mean P3b amplitudes in Figure 4).

As expected, in all four blocks, mean P3b amplitudes increased for targets as compared with standards. In the blocks in which both ALL and SOME were targets (Figures 3A,C), there was no significant difference between the mean P3b amplitudes elicited by these two stimuli. In the blocks in which only ALL was a target (Figures 3B,D), there was no difference between standard-SOME and the other standards in the mismatch target block; but standard-SOME elicited significantly larger P3b amplitudes than other standards in the match target block (Figure 3B). Moreover, there was a significant difference between P3b amplitudes elicited by standard-SOME and target-ALL in the match target block (Figure 3B), but only a marginal one in the mismatch target block (Figure 3D).

In sum, our oddball paradigm delivered the expected effects, but standard-SOME in the match target block elicited high
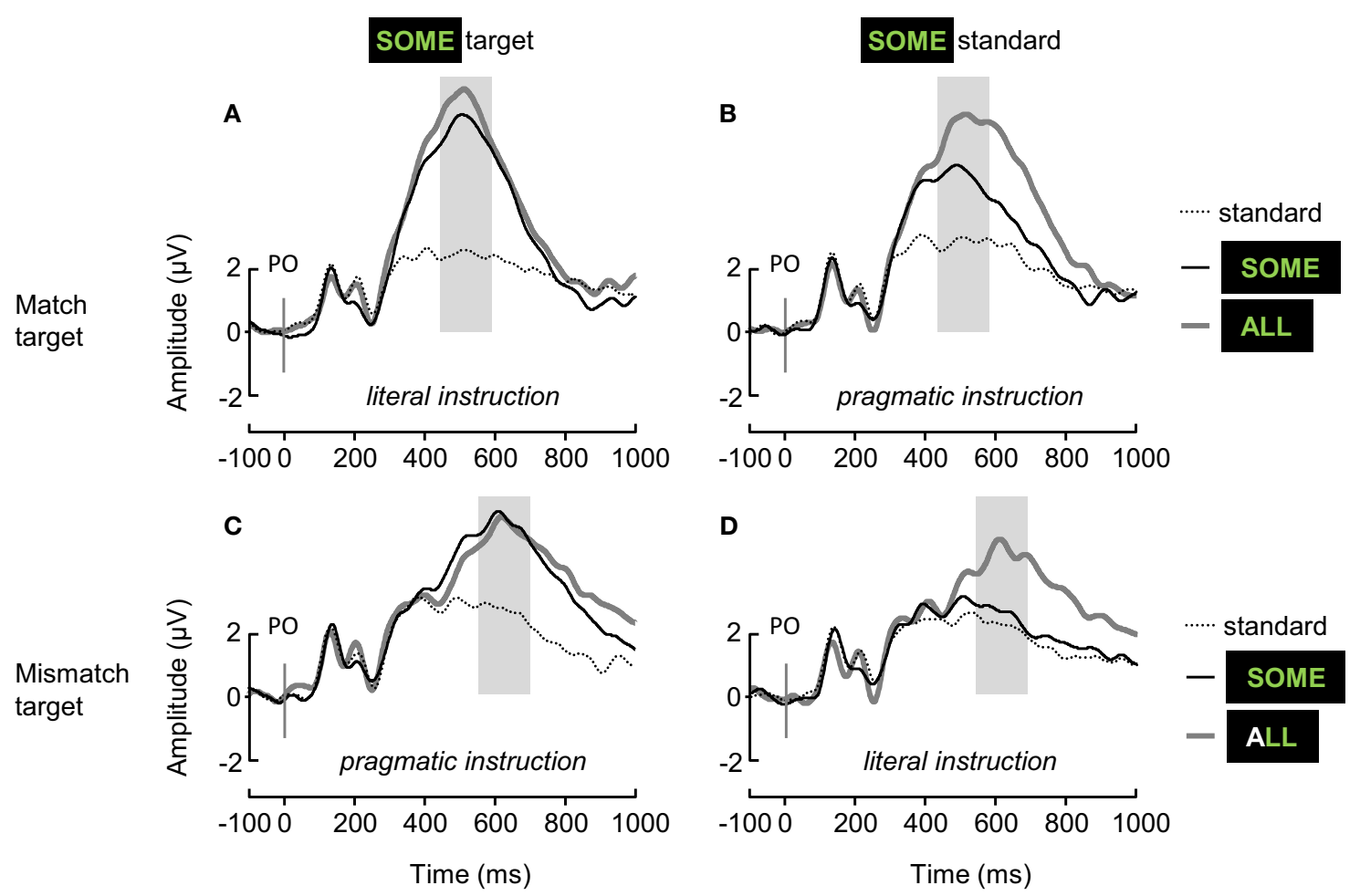

FIGURE 3 | Grand-average ERP waveforms elicited over the Parieto-Occipital region (linear derivation of Pz, PO3, PO4, POz) by standard items (dotted gray lines), unambiguous target-ALL (solid gray lines), and ambiguous-SOME (solid black lines), depending on the Block type (A,B, match target; C,D, mismatch target), and the status of ambiguous-SOME (A,C, target; B,D, standard). In italics: the context of interpretation of ambiguous-SOME. The shaded areas represent the time-windows used for the analysis of P3b mean amplitudes. 


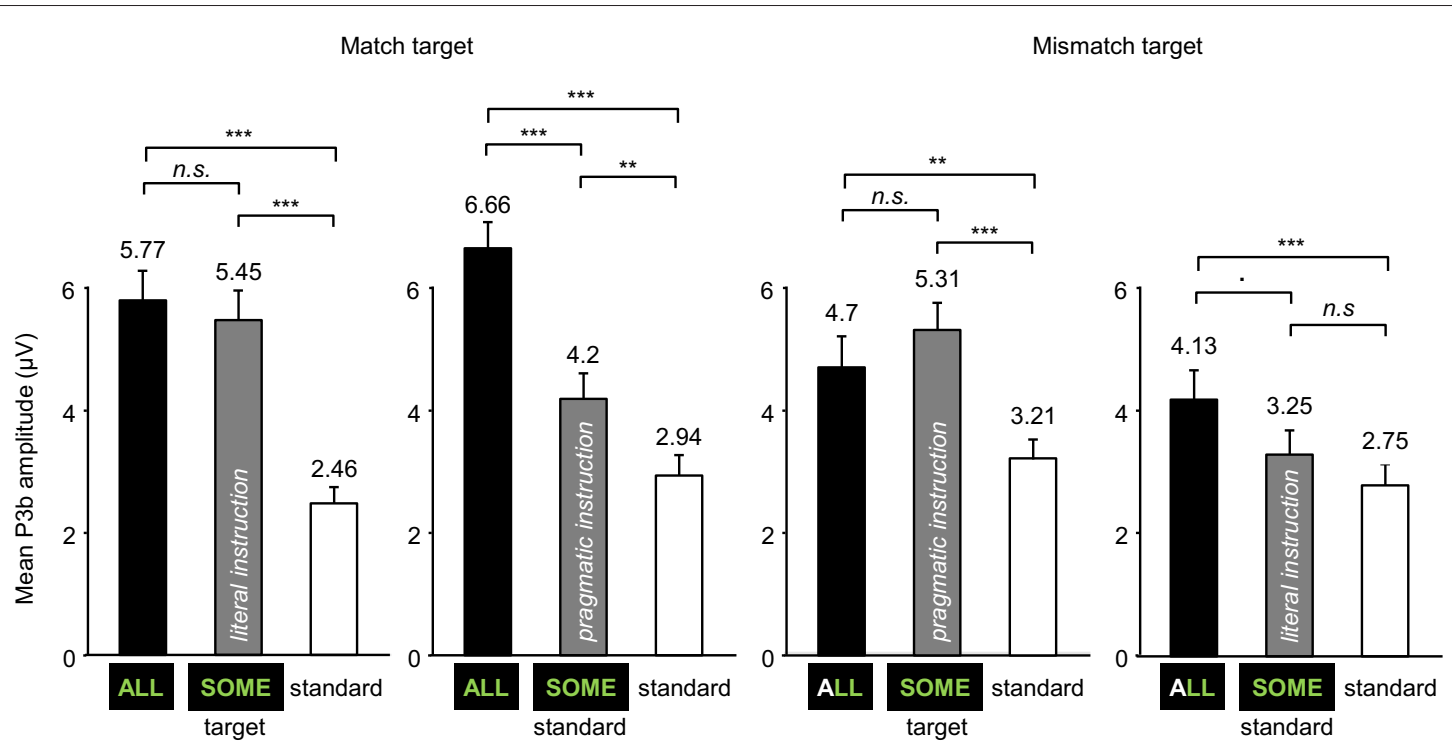

FIGURE 4 | Mean P3b amplitudes elicited over the Parieto-Occipital region (Pz, PO3, PO4, POZ) by ALL, SOME, and standards in each of the four experimental blocks (error bars represent standard errors of the mean). ${ }^{* \star} p<0.001,{ }^{* *} p<0.01,{ }^{*} p<0.05, \cdot p<0.1$.
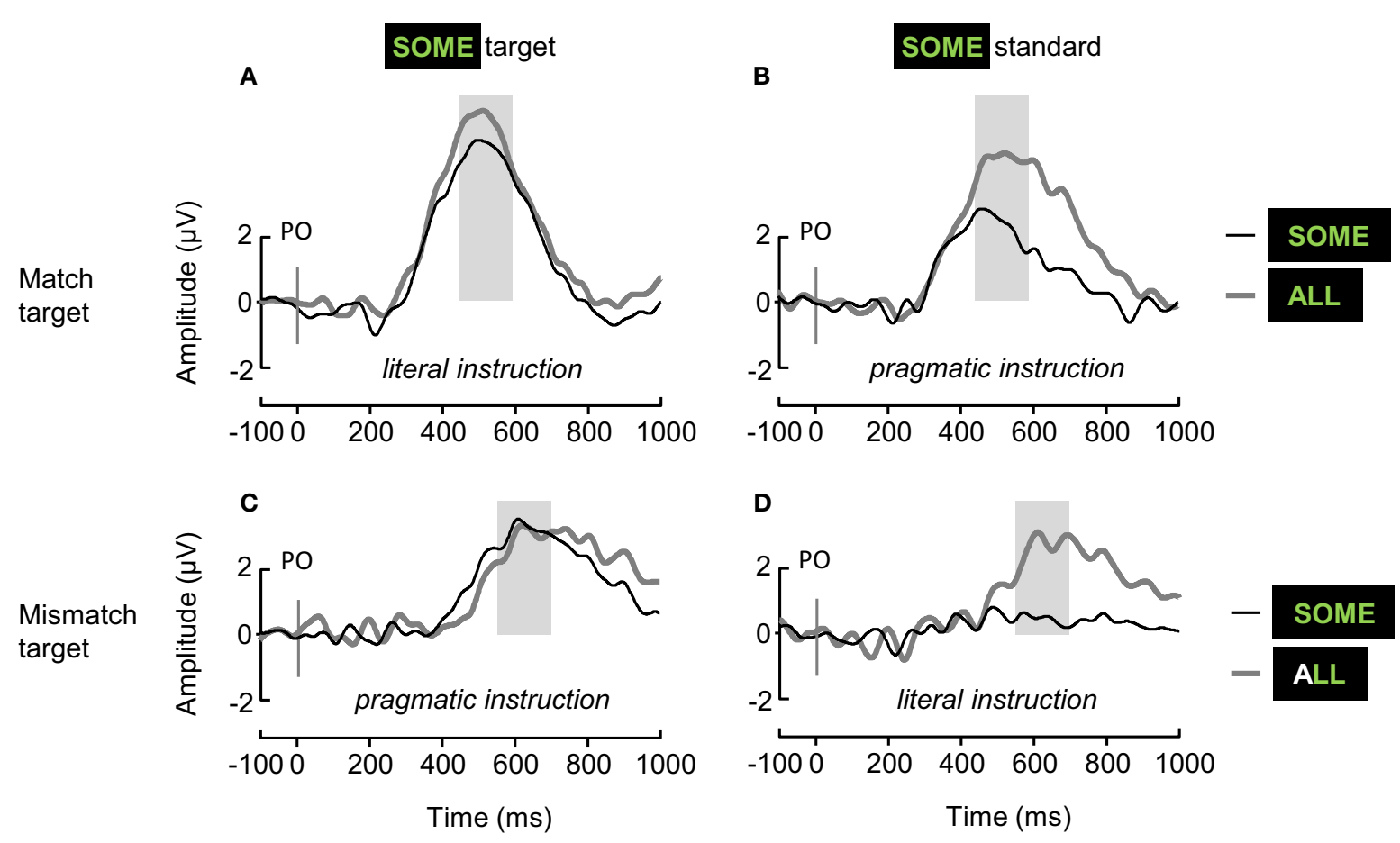

FIGURE 5 | Grand-average difference ERP waveforms elicited over the Parieto-Occipital region (linear derivation of Pz, PO3, PO4, POz) by unambiguous target-ALL (gray lines), and ambiguous-SOME (black lines), depending on the Block type (A,B, match target; C,D, mismatch target), and the status of ambiguous-SOME (A,C, target; B,D, standard). In italics: the context of interpretation of ambiguous-SOME. The shaded areas represent the time-windows used for the analysis of P3b effects.

P3b amplitude (Figure 3B). In this block, the targets were matches and SOME was to be considered pragmatically, therefore a mismatch, and thus be ignored. Participants managed to ignore the pragmatically mismatched version of SOME very well (accuracy: 90.7\%, see Section 3.2.1) but ERPs look as if they had been elicited by a target. However, the difference between standard-SOME and target-ALL in the mismatch target block was also less than expected (Figure 3D). In this block in which the 


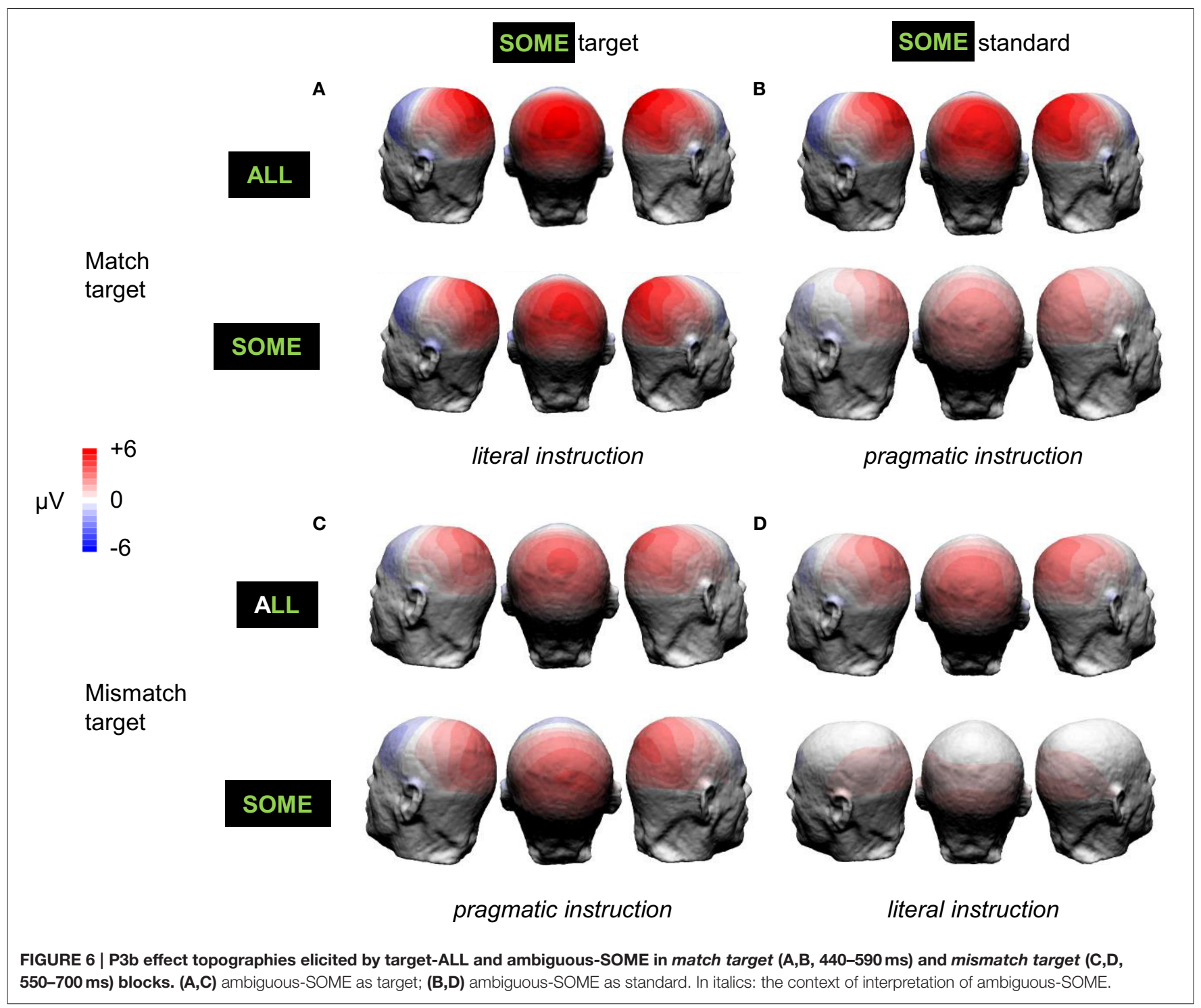

only target was ALL, SOME had to be considered literally, so a match and thus had to be ignored. The participants managed to ignore standard-SOME very well (accuracy 93.4\%), but although corresponding P3b amplitudes were not significantly different from those elicited by the other standards, they only marginally differed from those elicited by target-ALL. We further discuss these results below. Recall that standard-SOME was rarer than the other standards in the blocks (see Section 2.2.2).

In order to investigate the effect of the interpretation of ambiguous-SOME (literal or pragmatic), we calculated P3b effects: target-ALL P3b minus standards P3b, and ambiguousSOME P3b minus standards P3b; see Figure 5 for grandaverage difference ERP waveforms and Figure 6 for P3b effect topographies.

The first regression model revealed a significant 4-way interaction between Block type (match or mismatch target), Status of SOME (target or standard in the experimental block),
Stimulus (target-ALL or ambiguous-SOME) and Pragmatism score $\left[F_{(1,1039.86)}{ }^{9}=6.97, p<0.01\right]$.

Analyses for target-ALL and ambiguous-SOME separately showed a significant effect of Block type for target-ALL $\left[F_{(1,37.85)}=25.56, p<0.001\right]$ and no effect of, or interaction with, the status of SOME in the block or Pragmatism score. In sum, the P3b effect elicited by target-ALL was reduced in mismatch target blocks, regardless of Pragmatism score, and regardless of the status of SOME.

As regards ambiguous-SOME, the first model showed the expected 3-way interaction between Block type (match or mismatch target), Status of SOME (target or standard in the block) and Pragmatism score $\left[F_{(1,39.4)}=5.67, p<0.05\right]$.

\footnotetext{
${ }^{9}$ The random structure had to be simplified for this model and therefore does not include the 3-way interaction Block type $\times$ Status of SOME $\times$ Stimulus as bysubject random slope but only the Block type and the Status of SOME $\times$ Stimulus interaction. This simplification was determined based on the rand function of lmerTest (Kuznetsova et al., 2014).
} 
There was also a significant effect of Block Type $\left[F_{(1,36.96)}=\right.$ 7.72, $p<0.01]$ and a significant effect of Status $\left[F_{(1,37.03)}=\right.$ 20.2, $p<0.001$ ], but no significant interaction between the two $\left[F_{(1,37.45)}=2.18, p=0.15\right]$. These effects, and the absence of interaction between them, suggest that whereas standardSOME elicited the expected reduced P3b effects as compared with target-SOME, it was not processed as a typical standard (it was rarer than the other standards) in any of the blocks. Furthermore, it must be noted that SOME was a target in other blocks, it was the only stimulus highlighted by special instructions and was thus task-relevant stimulus even when it was a standard and required no response. The difference that one can see on the figures between standard-SOME in the match (Figures 5B, 6B) and the mismatch target blocks (Figures 5D, 6D) is similar to that found for target-SOME and target-ALL when comparing across blocks. In other words, this effect is probably one of Block type rather than an effect of the interpretation of SOME, see below.

Analyses for standard-SOME and target-SOME separately showed, for standard-SOME, only a marginal effect of Block type $\left[F_{(1,37.83)}=3.46, p=0.07\right]$. The P3b effect elicited by standard-SOME decreased by only $0.78 \mu \mathrm{V}$ (model estimate) in the mismatch target block (SOME standard match in its literal interpretation, Figures 5D, 6D) compared with the match target block (SOME standard mismatch in its pragmatic interpretation, Figures 5B, 6B). We expected here a possible interaction with Pragmatism score but found none.

As regards target-SOME, analyses revealed the expected significant interaction between Block type and Pragmatism score $\left[F_{(1,36.88)}=6.72, p<0.05\right]$. Analyses for the Block types separately showed a significant effect of Pragmatism score on P3b effect elicited by target-SOME in the match target block [literal interpretation of some, Figures 5A, 6A, $F(1,37)=4.55$, $p<0.05$ ], but no effect of Pragmatism score on P3b effect elicited by target-SOME in the mismatch target block (pragmatic interpretation of some, Figures 5C, 6C, $p>0.3$ ). In sum, the expected effect of Pragmatism score was only measurable when

TABLE 3 | Differences in P3b mean amplitudes.

\begin{tabular}{lcc}
\hline Block type & Estimate (SE) & $\boldsymbol{p}$ \\
\hline MATCH TARGET & & \\
Standard vs. target-ALL & $3.27(0.42)$ & $<0.001$ \\
Standard vs. target-SOME & $2.94(0.43)$ & $<0.001$ \\
Target-ALL vs. target-SOME & $-0.33(0.27)$ & $\mathrm{n} . \mathrm{s}$ \\
Standard vs. target-ALL & $3.71(0.34)$ & $<0.001$ \\
Standard vs. standard-SOME & $1.26(0.39)$ & $<0.01$ \\
Standard-SOME vs. target-ALL & $2.45(0.39)$ & $<0.001$ \\
MISMATCH TARGET & & \\
Standard vs. target-ALL & $1.42(0.36)$ & $<0.01$ \\
Standard vs. target-SOME & $2.04(0.27)$ & $<0.001$ \\
Target-ALL vs. target-SOME & $0.63(0.34)$ & $\mathrm{n} . \mathrm{s}$ \\
Standard vs. target-ALL & $1.36(0.30)$ & $<0.001$ \\
Standard vs. standard-SOME & $0.52(0.25)$ & $\mathrm{n} . \mathrm{s}$. \\
Standard-SOME vs. target-ALL & $0.84(0.35)$ & $<0.1$ \\
\hline
\end{tabular}

Estimates (in $\mu \mathrm{V}$ ) and p-values adjusted (Bonferroni's correction). participants had to take target-SOME in its literal interpretation (match target block, Figures 5A, 6A). In this condition, the P3b effect elicited by target-SOME decreased with an increase in Pragmatism score, see Figure 7.

\subsection{Questionnaire}

We looked at the results of the 52 participants who completed the questionnaire and included in the analysis the four independent variables of interest: SQ-R score, EQ score, IRIPT score (perspective-taking sub-scale) and AQ-Comm score (communication sub-scale) ${ }^{10}$. A generalized linear model (with inverse Gaussian/Wald distribution (link function $1 / \mu^{2}$ ) as exponential family) revealed that SQ-R score was the only significant predictor of Pragmatism score $\left[t_{(52)}=-2.206, p\right.$ $=0.032$; see in Appendix C, Figure A2 for the distribution, mean, median, SD and skewness values of the dependent and independent variables derived from the questionnaire, and Table A2 for estimates and model comparison]. Pragmatism score tended to increase with an increase in SQ-R score. Systemizing Quotient-Revised score significantly predicted some of the variance in Pragmatism score, whilst the other parameters failed to predict any part of it $^{11}$.

\footnotetext{
${ }^{10}$ We verified that there was no problem of multicollinearity calculating the variance inflation factors using the vif function of the R package car (Fox and Weisberg, 2011).

${ }^{11}$ Fitting linear models with transformed Pragmatism score (1/Pragmatism score ${ }^{2}$ ) which satisfy all of the linear model assumptions as assessed by the function gvlma of the R package gvlma (Pena and Slate, 2014) (whereas linear models with untransformed Pragmatism score led to comparable results but violated the normality of the error distribution assumption), we obtained similar results. $\mathrm{R}^{2}$ final linear model (SQ-R only predictor): $0.11 . \eta_{p}^{2}$ initial linear model: SQ-R: 0.13 , EQ: 0.001, PT: 0.03, AQ-Comm: 0.001.
}

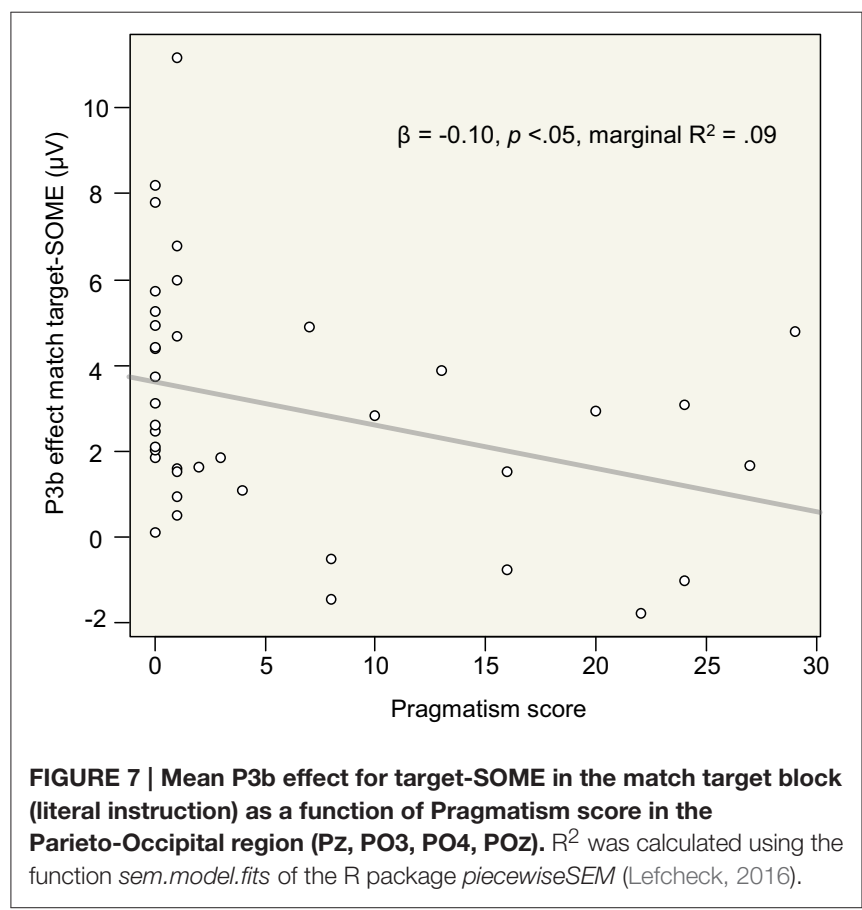




\section{DISCUSSION}

\subsection{Behavioral Responses}

Participants made fewer errors when target-SOME was to be taken in its literal (at-least-some) rather than its pragmatic (some-but-not-all) interpretation. This result is consistent with the pervasive literal interpretation facilitation effect in sentence verification tasks (see e.g., Noveck and Posada, 2003; Bott and Noveck, 2004; De Neys and Schaeken, 2007; Chevallier et al., 2008; Bott et al., 2012). However, in our design, when ambiguousSOME was a target, interpretation (literal or pragmatic) and block context (match or mismatch target) were confounded, and the mismatch target experimental context led to generally more errors, that is also for unambiguous target-ALL. In other words, it was easier to detect match targets amidst mismatch standards than the reverse.

Turning to reaction times, when participants were instructed to take some in its literal interpretation (match target block), they needed more time to respond to target-SOME than to target-ALL, but the difference between the two target types was smaller when they had to consider target-SOME in its pragmatic interpretation (mismatch target block). This confirms that the literal facilitation effect observed on hit rates reflects a general facilitation effect of experimental context (Block type). Furthermore, taken together, the increase in hit rates and the slowdown in response speed for literal target-SOME resembles a speed-accuracy trade-off.

We consider here that the literal interpretation facilitation effect found previously in sentence verification tasks might be a general effect of context: it is easier to respond to a "true"/matching than a "false"/mismatching stimulus, even when the response required is the same (as in experiment 2 in Bott and Noveck, 2004, see below). In our experiment, the ambiguous stimulus SOME was always the same: it appeared with all its letters in green. However, it required a response in the match target block because it was a match and in the mismatch target block because it was a mismatch. In sentence verification tasks, participants have to respond e.g., "true" or "false" to Some elephants are mammals, or "agree" to Mary says the following sentence is true/false Some elephants are mammals (Bott and Noveck, 2004). In any case, SOME presented in isolation and statements such as Some elephants are mammals are under-informative, and some studies pointed out that the infelicity of under-informativeness probably never goes unnoticed (Feeney et al., 2004; Antoniou and Katsos, 2011, see Section 1). When interpretation is constrained by instructions, responding pragmatically, that is dealing with "false"/mismatching items, appears a harder task than responding literally, that is dealing with "true"/matching items. When interpretation is not constrained, participants can opt for the easy or the harder task based on extraneous variables. In other words, we suggest here that the observed cognitive cost of the pragmatic interpretation of some in sentence verification tasks may not entirely originate in deriving the scalar inference per se (Bott and Noveck, 2004; Bott et al., 2012) but also in the particular task involved (see also Marty and Chemla, 2013).

\subsection{P3b Brain Responses}

The P3b is a late peaking positive wave from the P300 family of components (see e.g., Donchin, 1981; Polich, 2007). Its amplitude tends to increase with the propensity of a stimulus to disrupt a sequence of repetitive or ordered events within a predictable sequence. The $\mathrm{P} 3 \mathrm{~b}$ is expected to be of maximum amplitude in response to stimuli that are most target-like, especially if a response is to be produced by the participant, when stimuli and/or task complexity requires extended processing beyond mere perceptual processing and categorization.

P3b brain responses recorded for the control target stimulus all corroborated the effect of experimental context observed on hit rates and response times. It was easier to detect match items amidst mismatch items than the reverse. For the target some, there was an interaction between task specific demands and Pragmatism score. Brain responses to some literal in the match target context decreased with an increase in Pragmatism score. In other words, the more intolerant to pragmatic violations the participant, the weaker the $\mathrm{P} 3 \mathrm{~b}$ response to literal target some. As regards the pragmatic interpretation of some in the mismatch target block, no effect of Pragmatism score on P3b effect elicited by the target was measurable. As for the case of some when it was a standard, we found no interaction with Pragmatism score.

Brain responses corroborated behavioral results: it is more difficult to detect mismatches amid matches than matches amid mismatches, from a semantic or a pragmatic point of view. We found no tangible evidence of cost or delay associated with scalar inference computation (having to infer "not all" from some) per se when controlling for specific task demands. In this sense, our results are inconsistent with a two-step contextdriven model (literal meaning first and optional SI enrichment) as experimental pragmatics has it. Tomlinson et al. (2013) found that when verifying under-informative sentences such as "Some elephants are mammals," average mouse paths initially moved toward "true" before they changed direction to select "false." They concluded that SIs are understood in two steps: literal and then pragmatic. However, it is difficult to understand why they invoke such two-step processing model only for "Some elephants are mammals" and not for "No elephants are insects" which produces a comparable response delay. The task seems equally difficult in both cases: there are two consistent linguistic-semantic cues but the response to produce is inconsistent with them (see Urbach and Kutas, 2010; Urbach et al., 2015, for ERP evidence of partial incremental interpretation of quantifiers; and Clark and Chase, 1972, on the processing of "double negative"). Let's imagine a simplified incremental algorithm behind a sentence verification task. For instance, in the case of "Some elephants are mammals": some (EXIST) elephants are mammals (EXIST), intended response is "false." For "No elephants are insects": no ( $\neg$ EXIST) elephants are insects ( $\neg$ EXIST), intended response is "true." Thus, the observed delay may be due to the fact that the response intended has been counter-primed twice. And indeed, this never happened in the other control sentences in Tomlinson et al. (2013) . Arguably, judging "No elephants are insects" as "true" is not a pragmatic response because it corresponds to the truth value or logical value, of the sentence. But, it could also 
be argued that the spontaneous interpretation of "No elephants are insects" is "false." The double negation elimination may be a valid rule of classical logic (the so-called rule of replacement or inference, related to the principle of non-contradiction) but it is not systematically applied, as in the case of the non-standard but frequent double negative in English (e.g., I didn't say nothing) which resolves to a negative. In sum, whatever the position one adopts, it is difficult to see why the processing of "Some elephants are mammals" ("false") would be less "automatic" than the processing of "No elephants are insects" ("true"). The "automatic" computational process appears nonetheless to be more than a one-stage process in sentence verification tasks: it involves (i) accessing the quantifier's value, (ii) computing the semantics of the embedded proposition, (iii) computing the relationship between the quantifier and the embedded proposition (with a literal output for the some-sentence and a wrong/contradictory output for the no-sentence), and (iv) evaluating the truth value of the sentence in the world. The third stage is easy to complete $($ EXIST + EXIST $=$ true, or $\neg$ EXIST $+\neg$ EXIST $=$ false $)$, but the output of fourth stage must be the reverse of the previous stage in order to comply with world knowledge. This might explain why children tend to respond true to under-informative statements such as "Some elephants are mammals" more often than adults, and why adults under cognitive load (De Neys and Schaeken, 2007; Marty and Chemla, 2013) or time pressure (Bott and Noveck, 2004; Chevallier et al., 2008) do the same: they are making errors. More generally, the underlying process could be something like "if there is a mismatch or a contradiction resolve it," and what is important is the value of the mismatch or contradiction to resolve. It could explain why we can encourage adults to be more "logical," and children to be more "pragmatic" (see e.g., Noveck, 2001). It could also explain why a child so spontaneously says that Charlotte who has eaten all of the sweets is a liar when she says that she has eaten some of them (see Feeney et al., 2004): the brain is more interested in this than in verifying "Some elephants are mammals" because the former has some value. In this sense, the process is also "context-driven." Recall that certain specific semantic contexts such as antecedents of conditionals seem to block the "not all" interpretation of some, and that in contexts in which the speaker is assumed to have insufficient knowledge of the situation, the hearer does not necessarily access the "not all" interpretation (see Section 1).

The relationship between P3b amplitude and Pragmatism score provided insights into inter-individual variability. Along with a higher Pragmatism score, ambiguous-SOME (SOME) was less evident as a match target. This result suggests that P3b amplitude is a sensitive measure of cognitive flexibility and task adaptation. Participants generally managed to switch extremely well from one experimental block to another (match or mismatch target and literal or pragmatic interpretation of some). However, the relationship trend between intolerance to pragmatic violations and the reduction in the P3b effect elicited by literal some suggests that the pragmatic mismatch was less easy to suppress in order to treat some literally for some participants.

Alongside the discussion of our results, we have considered circumstantial evidence from other studies. Further investigation is required to characterize the nature of mismatch resolution processes we have hypothesized. Nevertheless, further research in experimental pragmatics should not only consider the principled difficulty of deriving scalar inferences but also that of dealing with mismatches in general (see also Shetreet et al., 2014).

\subsection{Evaluating Intolerance to Pragmatic Violations Based on Sentence Verification}

In the questionnaire, we used under-informative statements such as:

\section{(7) Some infants are young.}

in order to evaluate individual intolerance to pragmatic violations.

Although adults tend to be more intolerant to pragmatic violations generally, we found a relative proportion of participants who always, or almost always, strongly agreed with the under-informative statements (Pragmatism score of 0 or 1, 30 participants out of 52). This could be due to the fact that some of the statements we used were similar to (7), which is under-informative because all infants, by definition, are young, but others were like:

\section{(8) Some hammers have a handle.}

for which counter-examples or exceptions to the alternative all-statement can more easily be found (e.g., old or broken hammers could lack a handle, see also Guasti et al., 2005, pp. 690-691). In such cases, it can be argued that an informative alternative statement would be Most hammers have a handle rather than All hammers have a handle, which may render (8) more acceptable than (7). Indeed, when Feeney et al. (2004, experiment 3) used only statements of the sort of (8), half of their adult participants gave literal responses only. Guasti et al. (2005, pp. 690-691) argue that such statements can encourage participants to attempt figuring out exceptions to universal statements (e.g., All hammers have a handle) in order to make the under-informative statements more sensible and informative. However, Antoniou and Katsos (2011, experiment 2) who controlled the context provided to their participants (who judged, e.g., "There are suns on some of the cards" whilst looking at cards all featuring a sun) found that approximately half of the participants always gave literal responses. Therefore, the fact that the context of evaluation was not controlled in the case of under-informative statements such as (8) probably fails to explain alone why adults are sometimes unexpectedly tolerant to pragmatic violations. Yet participants could have resorted to another strategy leading to the observed preponderance of literal responses and a lack of variation in response types despite our use of a four-level rating scale rather than a binary forced-choice (true/false): the formal settings of the experiment might have invited participants to consider the some-statements as a test of logic.

In sum, even when controlling context of evaluation, and despite offering multiple possible choices rather than binary choices, participants appear to develop strategies idiosyncratic to the testing context. In any case, some participants seem to have opted for the easy task (dealing with true/matching rather than false/mismatching statements, see Section 4.1 and 4.2). If we are on the right track with this interpretation 
of the "agree"/"true"/logical/literal response mode in sentence verification tasks, it is in fact very pragmatic in a broad sense (for computational and human cognition saving principles, see e.g., Montague, 2007).

\subsection{Pragmatism and Systemizing}

The score the participants obtained in the Systemizing QuotientRevised questionnaire was the only significant parameter in the analysis of Pragmatism score. We discuss here some implications of this novel finding although the relationship between personality and cognitive traits and SI derivation requires further investigation.

Apart from "default models," pragmatic theories assume that SI derivation requires some sort of mind-reading since the hearer has to reason about speaker's knowledge and what she did not say (see Section 1). It could be considered surprising that we found no relationship between Empathy Quotient or Interpersonal Reactivity Index perspective-taking sub-scale and Pragmatism score. However, no information about the person producing the statements or other contextual information was provided to the participants and it was thus impossible to work out the producer's intentions or the context in which the statements were made. As regards Autism-Spectrum Quotient communication sub-scale and Pragmatism score, the tentative prediction made by Nieuwland et al. (2010, p. 343): "one possible prediction is that high AQ-Comm people are also more likely to respond 'true' to under-informative statements in a sentenceverification paradigm" was not supported (see also e.g., Heyman and Schaeken, 2015).

Our data suggest that there may be a relationship between systemizing and intolerance to pragmatic violations, such that Pragmatism score would tend to increase with SQ-R score. This could be seen as an inconsistent result if SQ- $\mathrm{R}$ is considered a proxy for logical reasoning. But this could in fact be expected if systemizing is taken to index participants' ability to work out the make up of the experiment and thus their ability to distinguish those statements that are under-informative [e.g., (7) or (8) ] from others that are not, e.g.,:

Some birds live in cages.

However, the experimental context alone probably fails to account for our results because the questionnaire featured only 5 true and felicitous some-statements, and because some- and all-statements were intermixed with 213 other statements from the AQ, EQ, SQ-R, and IRI. Another explanation could be that the better the participants at systemizing, the more salient the lexical scale 〈all, some〉 and thus the easier the first step of SI derivation. As suggested by van Tiel et al. (2016, pp. 32-33), hearers might rely on statistical regularities such as: if the speaker uses "some...," then she means "not all..." in order to derive SIs. According to Baron-Cohen (2008, p. 66), systemizing leads to identification of rules of the following form: "If $\mathrm{X}$ (operation) occurs, A (input) changes to B," and thus a strong sensitivity to patterns. In other words, it is possible that the better the participants at systemizing, the greater the likelihood of some meaning not all.
The trend for a positive relationship between intolerance to pragmatic violation and systemizing skills also makes sense in light of the literature on high-functioning autism and Asperger's syndrome. Individuals with such cognitive style are assumed to experience difficulties with pragmatics, however they are as intolerant to pragmatic violations as controls (whether they are adults, Pijnacker et al., 2009; or children, Chevallier et al., 2010). Since they are usually very good at systemizing whilst scoring low on EQ and high on AQ (see e.g., Wheelwright et al., 2006), systemizing skills must help in sentence verification tasks. If we are on the right track with our interpretation of the "agree"/"true"/logical/literal response mode in sentence verification tasks as finally the pragmatic one (in a broad sense: save energy whenever possible), it is no longer expected from individuals with high-functioning autism or Asperger's syndrome to particularly opt for this response mode. Furthermore, since systemizing is linked with attention to detail and leads to the seeking of exact truth (Baron-Cohen, 2008, 2011), it makes sense that participants with high systemizing skills tend to agree less with statements that do not describe reality with high accuracy, that are not optimal.

\section{CONCLUSION}

Using a novel oddball paradigm with single words and recording hit rates, reaction times and brain activity whilst controlling for task demands, and collecting a measure of interindividual variation, we failed to replicate a straightforward literal interpretation facilitation effect. Crucially, we provided some evidence to explain why this effect may not be entirely construed as some models of experimental pragmatics have it. We suggest that scalar inference derivation also involves generic, possibly unconscious, albeit cognitively costly and context-driven, procedures for mismatch processing. We argue that the true "pragmatic," that is efficient, response to underinformative some-statements in sentence verification tasks is not "false"/“disagree"/rejection but "true"/“agree"/acceptance: it saves brain energy when not much is at stake.

Overall, we take the view that our data reveal a little more how flexible and adaptive the human cognitive system is.

\section{AUTHOR CONTRIBUTIONS}

Conception, design, and writing: $\mathrm{CB}$ and GT. Data collection and statistics: $\mathrm{CB}$.

\section{FUNDING}

This research was funded by the Swiss National Science Foundation (grant P2NEP1_155426, CB).

\section{ACKNOWLEDGMENTS}

The authors thank Louise Allen-Walker her assistance with data collection. 


\section{REFERENCES}

Antoniou, K., and Katsos, N. (2011). “Only some listeners reject under-informative utterances," in Poster Presented at the 4th Experimental Pragmatics Conference (XPRAG 2011) (Barcelona).

Baayen, R. H., Davidson, D. J., and Bates, D. (2008). Mixed-effects modeling with crossed random effects for subjects and items. J. Mem. Lang. 59, 390-412. doi: 10.1016/j.jml.2007.12.005

Baayen, R. H., and Milin, P. (2010). Analyzing reaction times. Int. J. Psychol. Res. 3, 12-28. doi: 10.21500/20112084.807

Banga, A., Heutinck, I., Berends, S. M., and Hendriks, P. (2009). Some implicatures reveal semantic differences. Linguistics 26, 1-13. doi: 10.1075/avt.26.02ban

Baron-Cohen, S. (2008). Autism, hypersystemizing, and truth. Q. J. Exp. Psychol. 61, 64-75. doi: 10.1080/17470210701508749

Baron-Cohen, S. (2009). Autism: the empathizing-systemizing (E-S) theory. Ann. N.Y. Acad. Sci. 1156, 68-80. doi: 10.1111/j.1749-6632.2009.04467.x

Baron-Cohen, S. (2011). Zero Degrees of Empathy: A New Theory of Human Cruelty. London: Penguin Books.

Baron-Cohen, S., and Wheelwright, S. (2004). The empathy quotient: an investigation of adults with asperger syndrome or high functioning autism, and normal sex differences. J. Autism Dev. Disord. 34, 163-175. doi: 10.1023/B:JADD.0000022607.19833.00

Baron-Cohen, S., Wheelwright, S., Skinner, R., Martin, J., and Clubley, E. (2001). The autism-spectrum quotient (AQ): evidence from asperger syndrome/highfunctioning autism, males and females, scientists and mathematicians. J. Autism Dev. Disord. 31, 5-17. doi: 10.1023/A:1005653411471

Barr, D. J., Levy, R., Scheepers, C., and Tily, H. J. (2013). Random effects structure for confirmatory hypothesis testing: keep it maximal. J. Mem. Lang. 68, 255278. doi: 10.1016/j.jml.2012.11.001

Bates, D. (2005). Fitting linear mixed models in R. R News 5, 27-30.

Bates, D., Maechler, M., Bolker, B., and Walker, S. (2014). Ime4: Linear MixedEffects Models Using Eigen and S4. R Package Version 1.1-6.

Bergen, L., and Grodner, D. J. (2012). Speaker knowledge influences the comprehension of pragmatic inferences. J. Exp. Psychol. 38, 1450-1460. doi: 10.1037/a0027850

Bott, L., Bailey, T. M., and Grodner, D. J. (2012). Distinguishing speed from accuracy in scalar implicatures. J. Mem. Lang. 66, 123-142. doi: 10.1016/j.jml.2011.09.005

Bott, L., and Noveck, I. (2004). Some utterances are underinformative: the onset and time course of scalar inferences. J. Mem. Lang. 51, 437-457. doi: 10.1016/j.jml.2004.05.006

Breheny, R., Ferguson, H. J., and Katsos, N. (2013). Taking the epistemic step: toward a model of on-line access to conversational implicatures. Cognition 126, 423-440. doi: 10.1016/j.cognition.2012.11.012

Breheny, R., Katsos, N., and Williams, J. (2006). Are generalised scalar implicatures generated by default? Cognition 100, 434-463. doi: 10.1016/j.cognition.2005.07.003

Carston, R. (1995). Quantity maxims and generalized implicature. Lingua 96, 213-244. doi: 10.1016/0024-3841(95)00016-S

Carston, R. (2004). "Truth-conditional content and conversational implicature," in The Semantics/Pragmatics Distinction, ed C. Bianchi (Stanford, CA: CSLI), 65-100.

Chevallier, C., Noveck, I., Bott, L., Lanza, V., Nazir, T., and Sperber, D. (2008). Making disjunctions exclusive. Q. J. Exp. Psychol. 61, 1741-1760. doi: 10.1080/17470210701712960

Chevallier, C., Wilson, D., Happé, F., and Noveck, I. (2010). Scalar inferences in autism spectrum disorders. J. Autism Dev. Disord. 40, 1104-1117. doi: 10.1007/s10803-010-0960-8

Chierchia, G. (2004). Scalar Implicatures, Polarity Phenomena and the Syntax/Pragmatic Interface. Oxford: Oxford University Press.

Clark, H. H., and Chase, W. G. (1972). On the process of comparing sentences against pictures. Cogn. Psychol. 3, 472-517.

Davis, M. H. (1980). A multidimensional approach to individual differences in empathy. JSAS Catalog of Sel. Doc. Psychol. 10:85.

Davis, M. H. (1983). Measuring individual differences in empathy: evidence for a multidimensional approach. J. Pers. Soc. Psychol. 44:113. doi: 10.1037/00223514.44.1.113
De Neys, W., and Schaeken, W. (2007). When people are more logical under cognitive load. Dual task impact on scalar implicature. Exp. Psychol. 54, 128-133. doi: 10.1027/1618-3169.54.2.128

Degen, J., and Tanenhaus, M. K. (2011). "Making inferences; the case of scalar implicature processing," in Proceedings of the 33rd Annual Conference of the Cognitive Science Society, eds L. Carlson, C. Hölscher, and T. Shipley (Austin, TX: Cognitive Science Society), 3299-3304.

Degen, J., and Tanenhaus, M. K. (2015). Processing scalar implicature: a constraintbased approach. Cogn. Sci. 39, 667-710. doi: 10.1111/cogs.12171

Delplanque, S., Silvert, L., Hot, P., Rigoulot, S., and Sequeira, H. (2006). Arousal and valence effects on event-related P3a and P3b during emotional categorization. Int. J. Psychophysiol. 60, 315-322. doi: 10.1016/j.ijpsycho.2005.06.006

Donchin, E. (1981). Surprise!...surprise? Psychophysiology 18, 493-513. doi: 10.1111/j.1469-8986.1981.tb01815.x

Duncan-Johnson, C. C., and Kopell, B. S. (1981). The stroop effect: brain potentials localize the source of interference. Science 214, 938-940. doi: $10.1126 /$ science.7302571

Feeney, A., Scrafton, S., Duckworth, A., and Handley, S. J. (2004). The story of some: everyday pragmatic inference by children and adults. Can. J. Exp. Psychol. 58, 121-132. doi: 10.1037/h0085792

Fosker, T., and Thierry, G. (2005). Phonological oddballs in the focus of attention elicit a normal p3b in dyslexic adults. Cogn. Brain Res. 24, 467-475. doi: 10.1016/j.cogbrainres.2005.02.019

Fox, J., and Weisberg, S. (2011). An R Companion to Applied Regression, 2nd Edn. Thousand Oaks, CA: Sage.

Gratton, G., Coles, M. G., and Donchin, E. (1983). A new method for off-line removal of ocular artifact. Electroencephalogr. Clin. Neurophysiol. 55, 468-484.

Grice, H. P. (1968). Logic and Conversation. Cambridge, MA: Harvard University Press.

Grodner, D. J., Klein, N. M., Carbary, K. M., and Tanenhaus, M. K. (2010). 'Some', and possibly all, scalar inferences are not delayed: evidence for immediate pragmatic enrichment. Cognition 116, 42-55. doi: 10.1016/j. cognition.2010.03.014

Guasti, T. M., Chierchia, G., Crain, S., Foppolo, F., Gualmini, A., and Meroni, L. (2005). Why children and adults sometimes (but not always) compute implicatures. Lang. Cogn. Process. 20, 667-696. doi: 10.1080/0169096 0444000250

Hartshorne, J. K., Snedeker, J., Liem Azar, S. Y.-M., and Kim, A. E. (2015). The neural computation of scalar implicature. Lang. Cogn. Neurosci. 30, 620-634. doi: 10.1080/23273798.2014.981195

Heyman, T., and Schaeken, W. (2015). Some differences in some: examining variability in the interpretation of scalars using latent class analysis. Psychol. Belg. 55, 1-18. doi: 10.5334/pb.bc

Horn, L. R. (1972). On the Semantic Properties of Logical Operators in English. Ph.D. thesis, UCLA.

Horn, L. R. (1989). A Natural History of Negation. Chicago, IL: University of Chicago Press.

Hunt, L., Politzer-Ahles, S., Gibson, L., Minai, U., and Fiorentino, R. (2013). Pragmatic inferences modulate N400 during sentence comprehension: evidence from picture-sentence verification. Neurosci. Lett. 534, 246-251. doi: 10.1016/j.neulet.2012.11.044

Jaeger, T. (2008) Categorical data analysis: away from anovas (transformation or not) and towards logit mixed models. J. Mem. Lang. 59, 434-446. doi: 10.1016/j.jml.2007.11.007

Katsos, N., and Bishop, D. V. (2011). Pragmatic tolerance: implications for the acquisition of informativeness and implicature. Cognition 120, 67-81. doi: 10.1016/j.cognition.2011.02.015

Katsos, N., Breheny, R., and Williams, J. (2005). "The interaction of structural and contextual constraints during the on-line generation of scalar inferences," in Proceedings of the 27th Annual Conference of the Cognitive Science Society, eds B. Bara, L. Barsalou, and M. Bucciarelli (Mahwah, NJ: Lawrence Erlbaum Associates), 1108-1113.

Kiss, G. R., Armstrong, C., Milroy, R., and Piper, J. (1973). An associative thesaurus of English and its computer analysis. Comput. Lit. Stud. 153-165.

Kuznetsova, A., Brockhoff, P. B., and Christensen, R. H. B. (2014). lmerTest: Tests in Linear Mixed Effects Models. R package version 2.0-20. 
Lefcheck, J. S. (2016). PiecewiseSEM: piecewise structural equation modeling in R for ecology, evolution, and systematics. Methods Ecol. Evol. 7, 573-579. doi: 10.1111/2041-210X.12512

Leifeld, P. (2013). texreg: conversion of statistical model output in $\mathrm{R}$ to ${ }_{\mathrm{HT}} \mathrm{T} \mathrm{X}$ and HTML tables. J. Stat. Softw. 55, 1-24. doi: 10.18637/jss.v055.i08

Levinson, S. C. (2000). Presumptive Meanings: The Theory of Generalized Conversational Implicature. Cambridge, MA: MIT Press.

Luck, S. J. (2005). An Introduction to the Event-Related Potential Technique. Cambridge, MA: The MIT Press.

Marty, P. P., and Chemla, E. (2013). Scalar implicatures: working memory and a comparison with only. Front. Psychol. 4:403. doi: 10.3389/fpsyg.2013.00403

McGill, R., Tukey, J. W., and Larsen, W. A. (1978). Variations of box plots. Am. Stat. 32, 12-16.

Montague, R. (2007). Your Brain is (almost) Perfect: How We Make Decisions. New York, NY: Plume Penguin Books.

Nieuwland, M., Ditman, T., and Kuperberg, G. (2010). On the incrementality of pragmatic processing: an ERP investigation of informativeness and pragmatic abilities. J. Mem. Lang. 63, 324-346. doi: 10.1016/j.jml.2010. 06.005

Noveck, I. (2001). When children are more logical than adults : experimental investigations of scalar implicature. Cognition 78, 165-188. doi: 10.1016/S00100277(00)00114-1

Noveck, I., and Posada, A. (2003). Characterising the time course of an implicature. Brain Lang. 85, 203-210. doi: 10.1016/S0093-934X(03)00053-1

Otterbein, S., Abel, C., Heinemann, L. V., Kaiser, J., and Schmidt-Kassow, M. (2012). P3b reflects periodicity in linguistic sequences. PLoS ONE 7:e51419. doi: 10.1371/journal.pone.0051419

Pena, E. A., and Slate, E. H. (2014). gvlma: Global Validation of Linear Models Assumptions. R Package Version 1.0.0.2

Picton, T. W. (1992). The P300 wave of the human event-related potential. J. Clin. Neurophysiol. 9, 456-479. doi: 10.1097/00004691-199210000-00002

Picton, T. W., Bentin, S., Berg, P., Donchin, E., Hillyard, S., Johnson, R., et al. (2000). Guidelines for using human event-related potentials to study cognition: recording standards and publication criteria. Psychophysiology 37, 127-152. doi: 10.1111/1469-8986.3720127

Pijnacker, J., Hagoort, P., Buitelaar, J., Teunisse, J.-P., and Geurts, B. (2009). Pragmatic inferences in high-functioning adults with autism and asperger syndrome. J. Autism Dev. Disord. 39, 607-618. doi: 10.1007/s10803-008-0661-8

Polich, J. (2007). Updating P300: an integrative theory of P3a and P3b. Clin. Neurophysiol. 118, 2128-2148. doi: 10.1016/j.clinph.2007. 04.019

Politzer-Ahles, S., and Fiorentino, R. (2013). The realization of scalar inferences: context sensitivity without processing cost. PLoS ONE 8:e63943. doi: 10.1371/journal.pone.0063943

Politzer-Ahles, S., and Gwilliams, L. (2015). Involvement of prefrontal cortex in scalar implicatures: evidence from magnetoencephalography. Lang. Cogn. Neurosci. 30, 853-866. doi: 10.1080/23273798.2015.1027235

R Core Team (2014). R: A Language and Environment for Statistical Computing. Version 3.1.0. Vienna: R Foundation for Statistical Computing.
Sassenhagen, J., Schlesewsky, M., and Bornkessel-Schlesewsky, I. (2014). The P600-as-P3 hypothesis revisited: Single-trial analyses reveal that the late EEG positivity following linguistically deviant material is reaction time aligned. Brain Lang. 137, 29-39. doi: 10.1016/j.bandl.2014.07.010

Shetreet, E., Chierchia, G., and Gaab, N. (2014). When some is not every: dissociating scalar implicature generation and mismatch. Hum. Brain Mapp. 35, 1503-1514. doi: 10.1002/hbm.22269

Sperber, D., and Wilson, D. (1995). Relevance, 2 Edn. Oxford: Blackwell.

Tavano, E., and Kaiser, E. (2010). "Processing scalar implicature: What can individual differences tell us?" in University of Pennsylvania Working Papers in Linguistics, Vol. 16, 1. Available online at: http://www.ling.upenn.edu/pwpl/

Thierry, G., and Kotz, S. A. (2008). The right hemisphere fails to orient to the negative valence of visually presented words. Neuroreport 19, 1231-1234. doi: 10.1097/WNR.0b013e328309f021

Tomlinson, J. M., Bailey, T. M., and Bott, L. (2013). Possibly all of that and then some: Scalar implicatures are understood in two steps. J. Mem. Lang. 69, 18-35. doi: 10.1016/j.jml.2013.02.003

Urbach, T. P., DeLong, K. A., and Kutas, M. (2015). Quantifiers are incrementally interpreted in context, more than less. J. Mem. Lang. 83, 79-96. doi: 10.1016/j.jml.2015.03.010

Urbach, T. P., and Kutas, M. (2010). Quantifiers more or less quantify on-line: Erp evidence for partial incremental interpretation. J. Mem. Lang. 63, 158-179. doi: 10.1016/j.jml.2010.03.008

van Tiel, B., van Miltenburg, E., Zevakhina, N., and Geurts, B. (2016). Scalar diversity. J. Semant. 33, 137-175. doi: 10.1093/jos/ffu017

Venables, W. N., and Ripley, B. D. (2002). Modern Applied Statistics with S, 4th $E d n$. New York, NY: Springer.

Wheelwright, S., Baron-Cohen, S., Goldenfeld, N., Delaney, J., Fine, D., Smith, R., et al. (2006). Predicting autism spectrum quotient (AQ) from the systemizing quotient-revised (SQ-R) and empathy quotient (EQ). Brain Res. 1079, 47-56. doi: $10.1016 /$ j.brainres.2006.01.012

$\mathrm{Wu}$, Y. J., and Thierry, G. (2013). Fast modulation of executive function by language context in bilinguals. J. Neurosci. 33, 13533-13537. doi: 10.1523/JNEUROSCI.4760-12.2013

Zhao, M., Liu, T., Chen, G., and Chen, F. (2015). Are scalar implicatures automatically processed and different for each individual? A mismatch negativity (MMN) study. Brain Res. 1599, 137-149. doi: 10.1016/j.brainres.2014.11.049

Conflict of Interest Statement: The authors declare that the research was conducted in the absence of any commercial or financial relationships that could be construed as a potential conflict of interest.

Copyright (c) 2016 Barbet and Thierry. This is an open-access article distributed under the terms of the Creative Commons Attribution License (CC BY). The use, distribution or reproduction in other forums is permitted, provided the original author(s) or licensor are credited and that the original publication in this journal is cited, in accordance with accepted academic practice. No use, distribution or reproduction is permitted which does not comply with these terms. 


\section{APPENDIX A}

TABLE A1 | All- and some-statements used in the questionnaire (see Section 2.2.1).

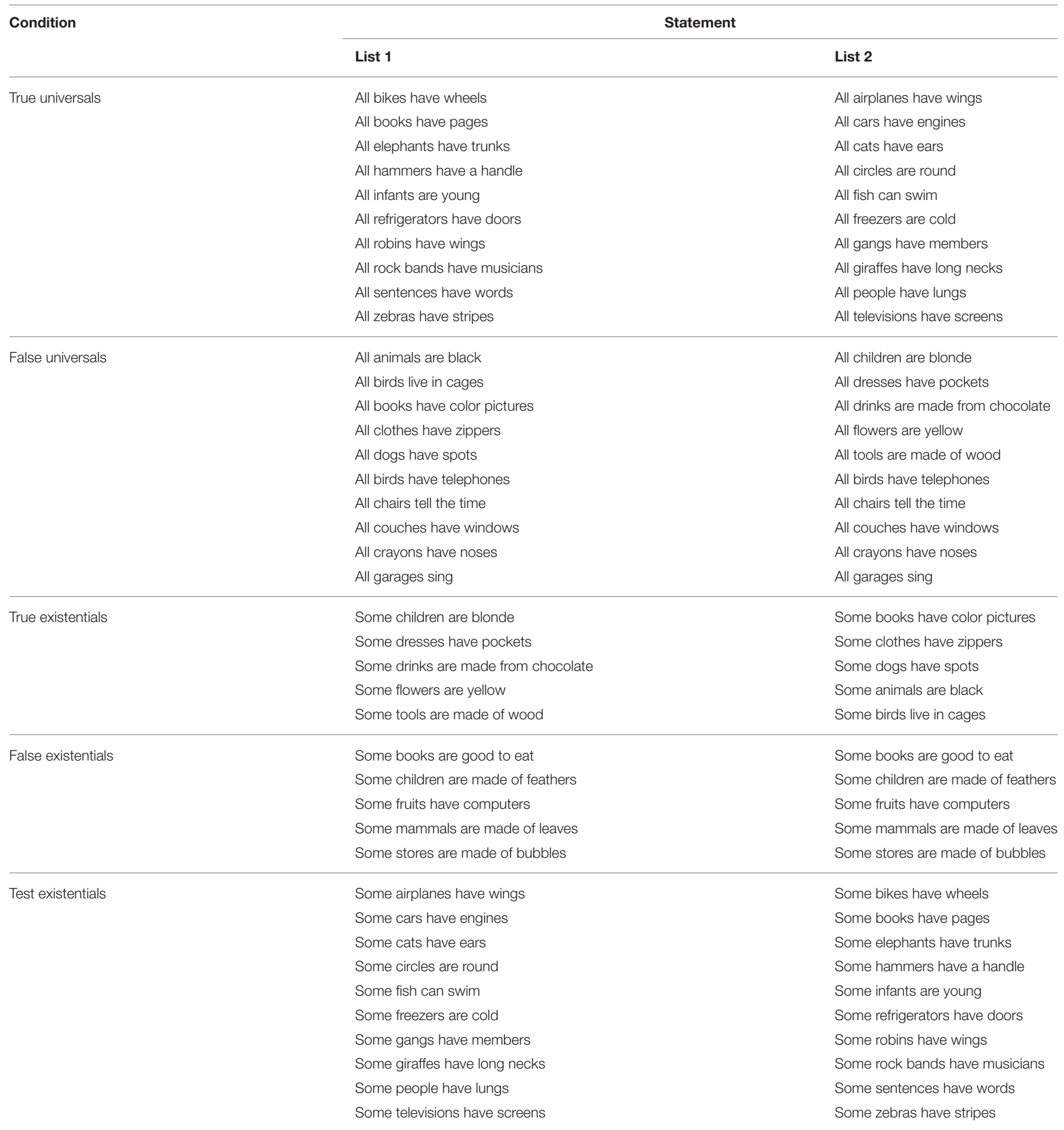




\section{APPENDIX B}

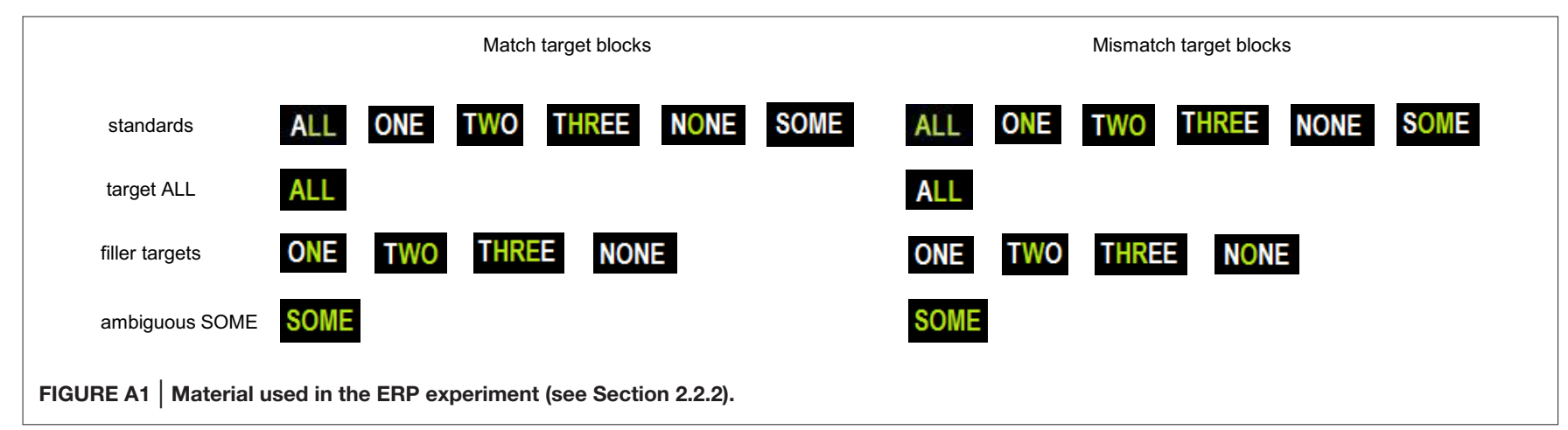

\section{APPENDIX C}

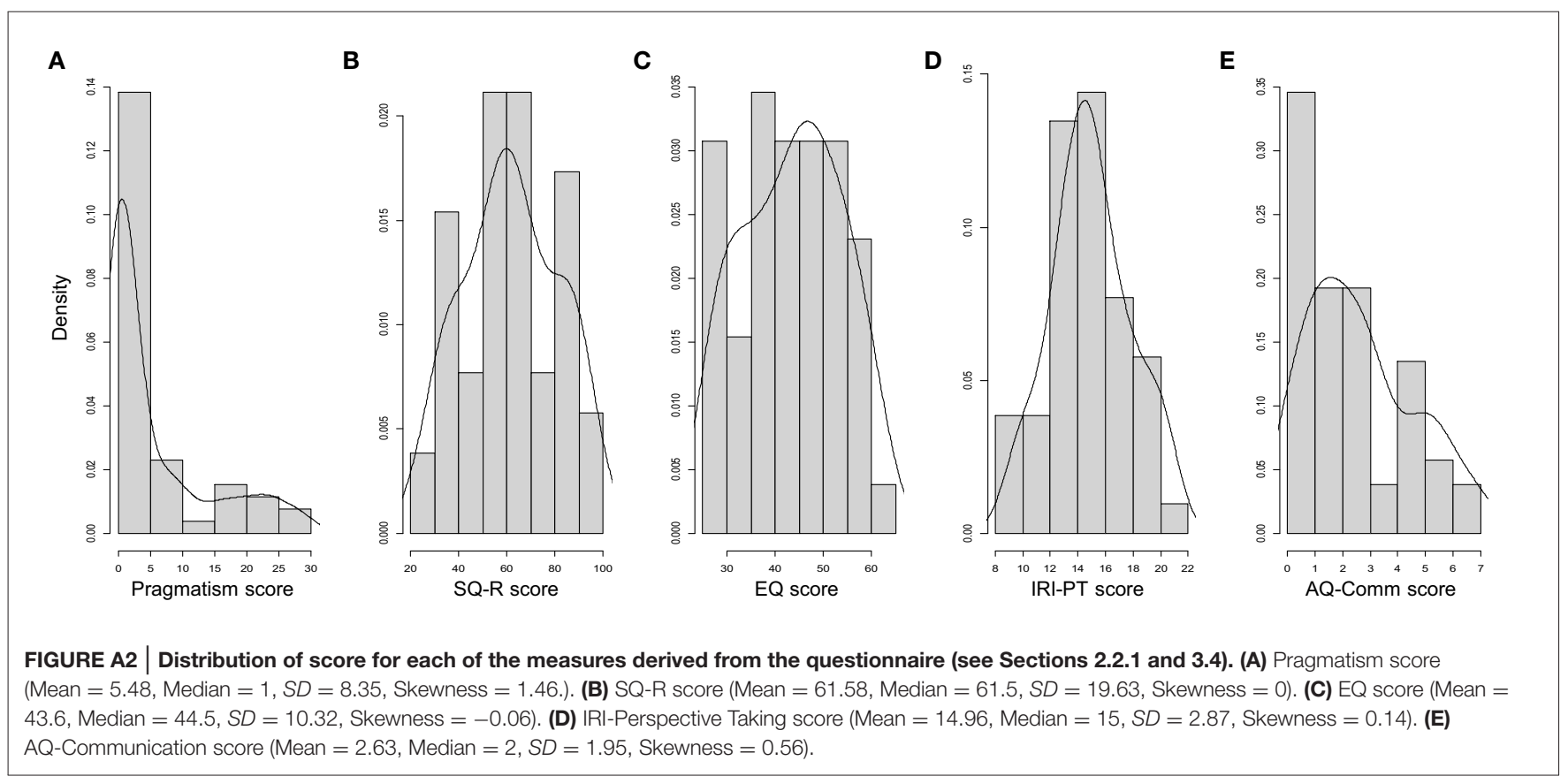


TABLE A2 | Model comparison (see Section 3.4).

\begin{tabular}{lrrr}
\hline & Null model & \multicolumn{1}{c}{ Initial model } & \multicolumn{1}{c}{ Final model } \\
\hline Intercept & $0.00417(0.00062)^{\star \star \star}$ & $0.00520(0.00434)$ & $0.00863(0.00224)^{\star \star \star}$ \\
SQ-R & & $-0.00007(0.00003)^{\star}$ & $-0.00007(0.00003)^{\star}$ \\
EQ & $-0.00001(0.00007)$ & \\
IRI-PT & $0.00026(0.00023)$ & \\
AQ-Comm & & $0.00006(0.00035)$ & \\
\hline AIC & 337.41 & 336.43 & 332.64 \\
BIC & 341.31 & 348.13 & 338.49 \\
Log Likelihood & -166.70 & -162.21 & -163.32 \\
Num. obs. & 52 & 52 & 52 \\
\hline
\end{tabular}

Estimates and standard errors (in brackets). ${ }^{\star \star \star} p<0.001,{ }^{* \star} p<0.01,{ }^{*} p<0.05$.

An inverse Gaussian distribution was used as family, negative estimates should be read as positive estimates, and positive estimates as negative ones. Table realized using the $R$ package texreg (Leifeld, 2013). 